AperTO - Archivio Istituzionale Open Access dell'Università di Torino

Investigation on the interconversion from DMF-solvated to unsolvated copper(ii) pyrazolate coordination polymers

This is a pre print version of the following article:

Original Citation:

Availability:

This version is available http://hdl.handle.net/2318/1770025

since 2022-01-19T12:43:37Z

Published version:

DOI:10.1039/D0CE00370K

Terms of use:

Open Access

Anyone can freely access the full text of works made available as "Open Access". Works made available under a Creative Commons license can be used according to the terms and conditions of said license. Use of all other works requires consent of the right holder (author or publisher) if not exempted from copyright protection by the applicable law. 


\title{
Investigation on the Interconversion from DMF Solvated to Unsolvated Copper(II) Pyrazolate Coordination Polymers
}

\author{
Corrado Di Nicola, ${ }^{\mathrm{a}, *}$ Alessia Tombesi, ${ }^{\mathrm{a}}$ Marco Moroni, ${ }^{\mathrm{b}}$ Rebecca Vismara, ${ }^{\mathrm{b}}$ Fabio Marchetti, \\ Riccardo Pettinari, ${ }^{\mathrm{c}}$ Luca Nardo, ${ }^{\mathrm{b}}$ Guglielmo Vesco, ${ }^{\mathrm{b}}$ Simona Galli, ${ }^{\mathrm{b} *}$ Silvia Casassa, ${ }^{\mathrm{d}}$ \\ Luciano Pandolfo, ${ }^{\mathrm{e} *}$ Claudio Pettinari ${ }^{\mathrm{a}}$
}

\footnotetext{
${ }^{a}$ School of Science and Technology, University of Camerino, Via S. Agostino 1, 62032 Camerino (MC), Italy.

${ }^{b}$ Dipartimento di Scienza e Alta Tecnologia, Università dell'Insubria, Via Valleggio 11, 22100 Como, Italy.

${ }^{c}$ School of Pharmacy, University of Camerino, Via S. Agostino 1, 62032 Camerino (MC), Italy.

${ }^{\mathrm{d}}$ Department of Chemistry, University of Turin, Via P. Giuria 5, 10125 Torino, Italy.

${ }^{\mathrm{e}}$ Department of Chemical Sciences, University of Padova, Via Marzolo 1, 35131 Padova, Italy.
}

\begin{abstract}
A series of copper(II) pyrazolates were synthesized employing different synthetic approaches. By refluxing either $\left[\mathrm{Cu}_{3}\left(\mu_{3}-\mathrm{OH}\right)(\mu-\mathrm{pz})_{3}\left(\mathrm{CH}_{3} \mathrm{COO}\right)_{2}(\mathrm{pzH})\right]$ or $\left[\mathrm{Cu}(\mu-\mathrm{pz})_{2} \cdot \mathrm{H}_{2} \mathrm{O}\right]_{\mathrm{n}}$ in water, $[\mathrm{Cu}(\mu-$ $\mathrm{pz})(\mu-\mathrm{OH})]_{\mathrm{n}}$ (1) was unexpectedly obtained. Whereas using microwave-assisted solvothermal synthesis, the compounds $\left[\mathrm{Cu}(\mu-4-\mathrm{Xpz})_{2}(\mu-\mathrm{DMF})\right]_{\mathrm{n}}\left(\mathbf{2}_{\mathbf{D M F}}-\mathbf{5}_{\mathrm{DMF}}\right)(4-\mathrm{Xpz}=4-\mathrm{Xpyrazolate}, \mathrm{X}=\mathrm{H}$, $\mathrm{Cl}, \mathrm{Br}, \mathrm{I})$ were isolated. As unveiled by powder X-ray diffraction, all the compounds are 1-D coordination polymers showing square planar trans-CuN $\mathrm{Cu}_{2}(\mathbf{1})$ or octahedral trans- $\mathrm{CuN}_{4} \mathrm{O}_{2}\left(\mathbf{2}_{\mathbf{D M F}^{-}}\right.$ $\mathbf{5}_{\text {DMF }}$ ) metal centers, reasonably involved in through-bond magnetic interactions (magnetic susceptibility in the range $0.91-1.56$ B.M.). Upon heating under inert atmosphere, $\mathbf{2}_{\mathbf{D M F}}-\mathbf{5}_{\mathbf{D M F}}$ lose DMF to give the corresponding low-crystallinity $\left[\mathrm{Cu}(\mu-4-\mathrm{Xpz})_{2}\right]_{\mathrm{n}}$ coordination polymers $\mathbf{2 - 5}$, of which only 3 was characterized in the past. In order to shed light on the local-level structural features of 2, 4 and 5, UV-Vis-NIR absorption and fluorescence emission spectroscopy measurements were performed, strongly suggesting a tetrahedral stereochemistry for the metal centres.
\end{abstract}

Keywords $\mathrm{Cu}(\mathrm{II})$ pyrazolates, coordination polymers, microwave-assisted solvothermal synthesis, powder X-ray diffraction, electronic-state transition spectroscopy. 


\section{Introduction}

Even though about thirty years have passed from the intuition of Robson and Hoskins ${ }^{1}$ that initiated the coordination polymers (CPs) age, the interest towards these compounds is far from being exhausted. Coordination polymers ${ }^{2-5}$ are inorganic-organic materials showing not only fascinating structural features, but also interesting functional properties and potential applications in relevant fields, such as luminescence, ${ }^{6-9}$ heterogeneous catalysis, ${ }^{10}$ magnetism, ${ }^{11-14}$ conductivity, ${ }^{15}$ nanoelectronics, ${ }^{16}$ to quote a few.

In the crystal structure of these compounds, rigid or flexible polytopic ligands, behaving as spacers, bridge metal ions or oxo-metallic clusters, behaving as nodes. The organic spacers that have been commonly employed in the construction of first-generation CPs are polytopic carboxylates, ${ }^{17,18}$ pyrazines and bipyridines. ${ }^{19}$ To date, a great number of CPs containing other nitrogen-donor ligands, such as poly(azolates) (pyrazolates, imidazolates, triazolates and tetrazolates) have been reported. ${ }^{20-24}$

In the past years, we have deeply investigated the interactions of $3 d$ transition metal ions with pyrazole (pzH) and monocarboxylates, synthesizing mono- and polynuclear complexes as well as CPs. Besides zinc(II), cadmium(II) and mercury(II) carboxylates, ${ }^{25,26}$ our interest has been mainly addressed to investigate how the reaction conditions between copper(II) carboxylates and pzH can influence the composition as well as the structural and functional properties of the final products. Noteworthy, we observed a different behaviour if the reactions among $\mathrm{Cu}$ (II) carboxylates and pzH were carried out in protic solvents $\left(\mathrm{H}_{2} \mathrm{O}\right.$, alcohols) or in $\mathrm{MeCN}$. In the first case, compounds based on the trinuclear triangular moiety $\left[\mathrm{Cu}_{3}\left(\mu_{3}-\mathrm{OH}\right)(\mu-\mathrm{pz})_{3}\right]^{2+}$, the charge of which is balanced by two carboxylate ions coordinated to the metal centre, were obtained (Scheme 1). These trinuclear complexes self-assemble in hexanuclear clusters through carboxylate bridges and form extended 1D, 2-D or 3-D CPs or supramolecular networks, displaying intriguing catalytic activity in the cycloalkane oxidation to alcohols. ${ }^{27-40,41}$ Completely different results were obtained when $\mathrm{Cu}$ (II) carboxylates were reacted with $\mathrm{pzH}$ in $\mathrm{MeCN}$, yielding the pale-pink 1-D CP $\left[\mathrm{Cu}(\mu-\mathrm{pz})_{2} \cdot \mathrm{H}_{2} \mathrm{O}\right]_{\mathrm{n}}$ independently from the carboxylate employed (Scheme 1). ${ }^{42-44}$ This compound reversibly loses water, yielding $\left[\mathrm{Cu}(\mu-\mathrm{pz})_{2}\right]_{\mathrm{n}}$. Besides water, $\left[\mathrm{Cu}(\mu-\mathrm{pz})_{2}\right]_{\mathrm{n}}$ is able to reversibly bind other small molecules such as $\mathrm{NH}_{3}$, changing its colour from beige to deep blue ${ }^{42}$ (Scheme 1).

Based on the above mentioned results, we decided to expand the investigation on novel coordination compounds having the $\left\{\mathrm{Cu}_{3}\left(\mu_{3}-\mathrm{OH}\right)(\mu-\mathrm{pz})_{3}\right\}^{2+}$ cluster or $\left\{\mathrm{Cu}(\mu-\mathrm{pz})_{2}\right\}$ fragment as secondary building unit (SBUs). Herein we report the results obtained upon refluxing either $\left[\mathrm{Cu}_{3}\left(\mu_{3}-\mathrm{OH}\right)(\mu-\mathrm{pz})_{3}\left(\mathrm{CH}_{3} \mathrm{COO}\right)_{2}(\mathrm{pzH})\right]$ or $\left[\mathrm{Cu}(\mu-\mathrm{pz})_{2} \cdot \mathrm{H}_{2} \mathrm{O}\right]_{\mathrm{n}}$ in water, and upon reacting copper(II) acetate hydrate and 4-Xpyrazole, $(\mathrm{X}=\mathrm{H}, \mathrm{Cl}, \mathrm{Br}, \mathrm{I})$ along solvothermal, microwave-assisted 
syntheses, using dimethylformamide (DMF) as solvent. The isolated compounds were characterized as per their crystal structure, thermal behaviour, under $\mathrm{N}_{2}$ and in air, and electronic-state spectroscopic properties.

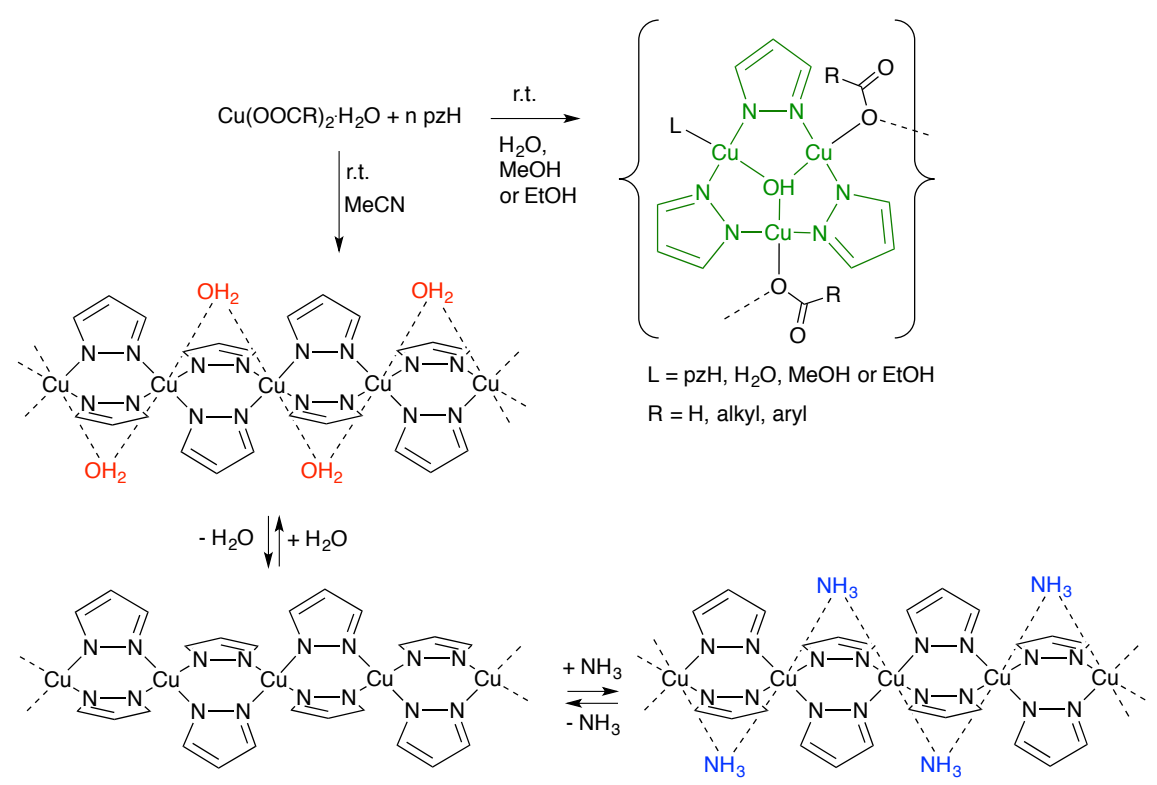

Scheme 1. Chemistry and reactivity of $\mathrm{Cu}(\mathrm{II})$ pyrazolate coordination compounds.

\section{Results and Discussion}

\subsection{Synthesis and preliminary characterization}

By refluxing either $\left[\mathrm{Cu}_{3}\left(\mu_{3}-\mathrm{OH}\right)(\mu-\mathrm{pz})_{3}\left(\mathrm{CH}_{3} \mathrm{COO}\right)_{2}(\mathrm{pzH})\right]$ or $\left[\mathrm{Cu}(\mu-\mathrm{pz})_{2} \cdot \mathrm{H}_{2} \mathrm{O}\right]_{\mathrm{n}}$ in water, compound $[\mathrm{Cu}(\mu-\mathrm{pz})(\mu-\mathrm{OH})]_{\mathrm{n}}$ (1) was obtained (Scheme 2) as a blue-purple microcrystalline powder insoluble in common solvents. This compound was previously isolated through a different procedure, but not completely characterized, by Mezei et al. ${ }^{45,46}$ Interestingly, the conversion of $\left[\mathrm{Cu}_{3}\left(\mu_{3}-\mathrm{OH}\right)(\mu-\mathrm{pz})_{3}\left(\mathrm{CH}_{3} \mathrm{COO}\right)_{2}(\mathrm{pzH})\right]$ or $\left[\mathrm{Cu}(\mu-\mathrm{pz})_{2} \cdot \mathrm{H}_{2} \mathrm{O}\right]_{\mathrm{n}}$ into $\mathbf{1}$ is reversible, the starting compounds being slowly reformed by cooling down the reaction mixtures and leaving them under stirring at room temperature for 12 hours (Scheme 2; IR evidences).

On the other hand, by reacting copper(II) acetate hydrate and pzH in DMF along a microwave-assisted solvothermal synthesis, a microcrystalline blue-violet powder was precipitated and characterized as $\left[\mathrm{Cu}(\mu-\mathrm{pz})_{2}(\mu-\mathrm{DMF})\right]_{\mathrm{n}}, \mathbf{2}_{\mathrm{DMF}}$, (Scheme 3). Similarly, copper(II) acetate hydrate and the substituted pyrazoles $4-\mathrm{XpzH}(\mathrm{X}=\mathrm{Cl}, \mathrm{Br}, \mathrm{I})$ afforded $\left[\mathrm{Cu}(\mu-4-\mathrm{Xpz})_{2}(\mu-\mathrm{DMF})\right]_{\mathrm{n}}\left(\mathbf{3}_{\mathbf{D M F}}\right.$, $\mathbf{4}_{\mathrm{DMF}}$ and $\mathbf{5}_{\mathrm{DMF}}$, for $\mathrm{X}=\mathrm{Cl}, \mathrm{Br}$, I, respectively; Scheme 3). 


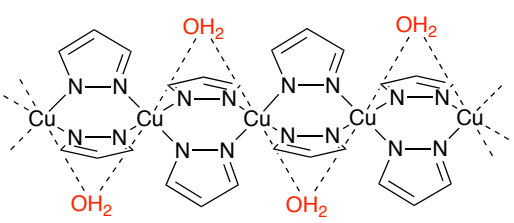

$\mathrm{H}_{2} \mathrm{O}$ ref. $\downarrow \uparrow \mathrm{H}_{2} \mathrm{O}$ r.t.
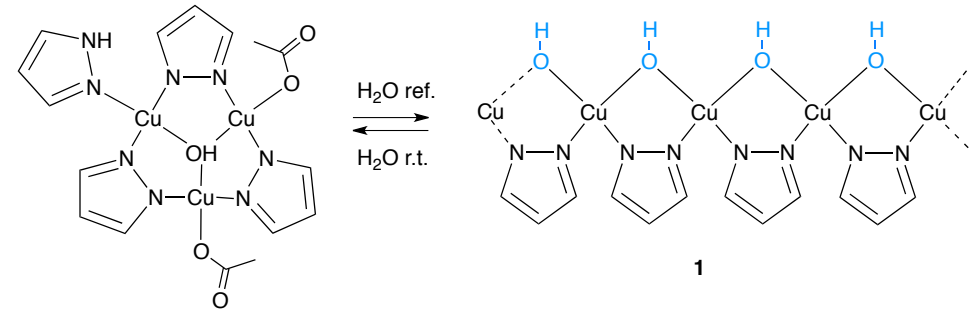

Scheme 2. Synthesis of compound 1 by using two different reagents.

It is important to underline that all the attempted reactions performed through conventional methods at room temperature or under reflux gave impure products difficult to separate and purify. By heating compounds $\mathbf{2}_{\mathrm{DMF}}-\mathbf{5}_{\mathrm{DMF}}$ at $453 \mathrm{~K}$ for two hours, DMF could be completely removed (IR spectroscopy evidences; see below), yielding the corresponding non-solvated forms (2-5, respectively), showing a different coordination at the metal ion (see the sections dedicated to the crystal structure description and the spectroscopic studies), hence a different colour (Figure 1).

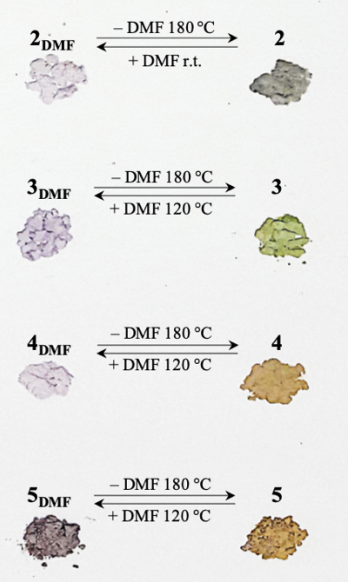

Figure 1. Colours of the solvated compounds $\mathbf{2}_{\mathrm{DMF}}-\mathbf{5}_{\mathrm{DMF}}$ and the non-solvated compounds $\mathbf{2 - 5}$. The colour change is induced by the (loss of) coordination of the DMF molecules to the copper(II) ions. 
The non-solvated forms can reacquire the original colour (and composition; IR evidences) in a few minutes by suspending them in DMF at r.t. (2) or at $393 \mathrm{~K} \mathrm{(3-5)}$ (Scheme 3).

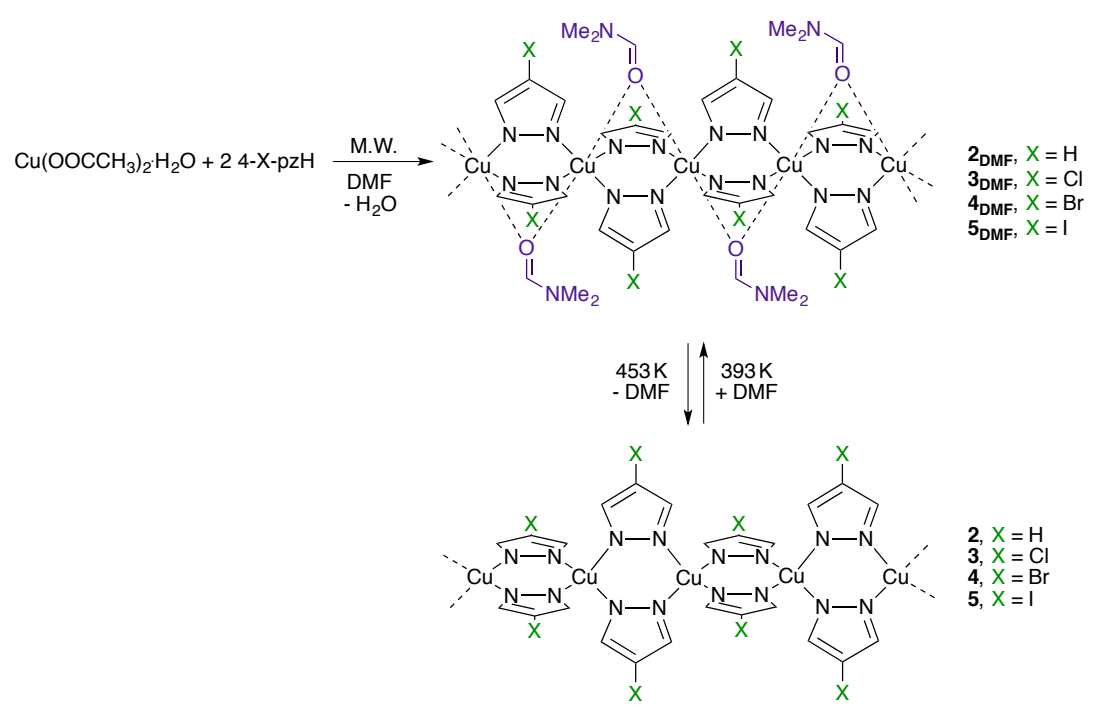

Scheme 3. Synthesis of compounds $\mathbf{2}_{\mathrm{DMF}}-\mathbf{5}_{\mathrm{DMF}}$ and $\mathbf{2 - 5}$.

The IR spectrum of 1 (Figure S1) shows the O-H bond stretching as a medium-intensity band at $3602 \mathrm{~cm}^{-1}$, the signal sharpness highlighting the absence of hydrogen-bond interactions, in agreement with what observed in the crystal structure (see section 2.2). The IR spectra of $\mathbf{2}_{\mathbf{D M F}}-\mathbf{5}_{\mathrm{DMF}}$ and 2-5 (Figure 2 for $\mathbf{3}_{\mathrm{DMF}}$ and 3; Figures S2-S4 for $\mathbf{2}_{\mathrm{DMF}}$ and $\mathbf{2}, \mathbf{4}_{\mathrm{DMF}}$ and $\mathbf{4}, \mathbf{5}_{\mathrm{DMF}}$ and $\mathbf{5}$ ) exhibit similar patterns, in agreement with their comparable structural features (see section 2.2). The presence of coordinated DMF is confirmed, in all cases, by an intense band in the range 1651-1655 $\mathrm{cm}^{-1}$ due to the $\mathrm{C}=\mathrm{O}$ stretching, shifted downfield with respect to free DMF $\left(1661 \mathrm{~cm}^{-1}\right)$. REF The $v(\mathrm{C}-\mathrm{Cl})$ stretching mode in the IR spectra of $\mathbf{3}_{\mathrm{DMF}}$ and $\mathbf{3}$ is found at 969 and $972 \mathrm{~cm}^{-1}$ (Figure 2), respectively, the small shift being possibly related to the absence of DMF in $\mathbf{3}$. As expected, in the IR spectra of $\mathbf{4}_{\mathrm{DMF}}, \mathbf{5}_{\mathrm{DMF}}, \mathbf{4}$ and $\mathbf{5}$ (Figures S3, S4) the absorption bands due to the $v(\mathrm{C}$-halide) stretching modes (halide $=\mathrm{Br}$ or I) appear at lower frequencies $\left(955 \mathrm{~cm}^{-1}\right.$ for $\mathrm{C}-\mathrm{Br}, 942 \mathrm{~cm}^{-1}$ for CI) due to the increase of the halogen atomic mass. 


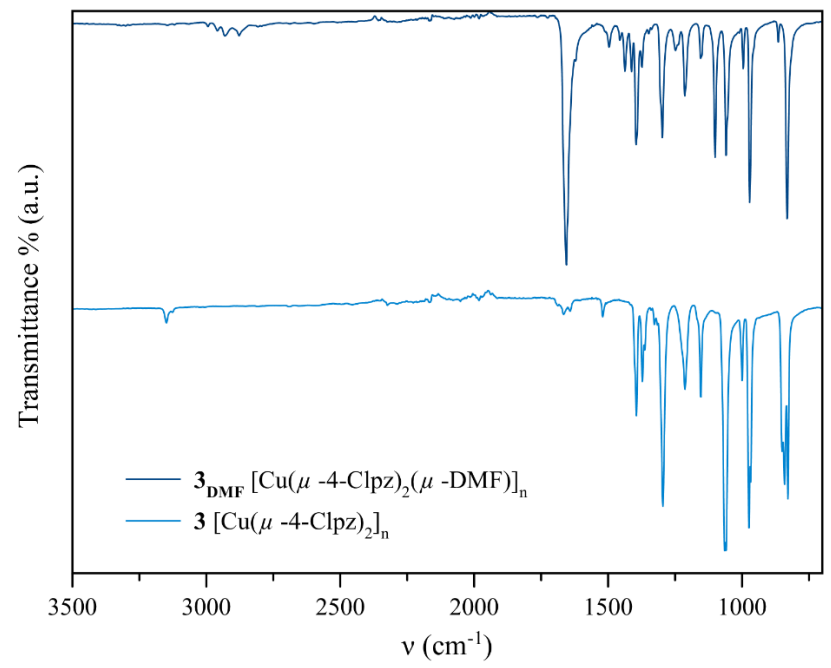

Figure 2. IR spectra of $\left[\mathrm{Cu}(\mu-4-\mathrm{Clpz})_{2}(\mu-\mathrm{DMF})\right]_{\mathrm{n}}\left(\mathbf{3}_{\mathrm{DMF}}\right.$, blue $)$ and $\left[\mathrm{Cu}(\mu-4-\mathrm{Clpz})_{2}\right]_{\mathrm{n}}(\mathbf{3}$, light blue $)$.

\subsection{Crystal Structure Analysis}

Compound 1 crystallizes in the orthorhombic space group Pbca. The asymmetric unit comprises one copper(II) ion, one $\mathrm{pz}^{-}$ligand and one $\mathrm{OH}^{-}$group, all in general positions. As assumed by Mezei and co-workers, ${ }^{45}$ the metal centres show the trans- $\mathrm{CuN}_{2} \mathrm{O}_{2}$ square planar stereochemistry, defined by the nitrogen atoms of two pz spacers and the oxygen atoms of two hydroxyl groups (Figure 3a; see the caption to the Figure for the main bond distances and angles at the metal ion). Both anions are exo-bidentate and define 1-D helices of collinear metal ions running along the [010] crystallographic direction (Figure 3b) with a $\mathrm{Cu} \cdots \mathrm{Cu}$ distance of 3.386(3) $\AA$ (half of the $b$-axis). The chains pack, staggered, along the [001] crystallographic direction defining a herringbone motif (Figure 3c). No hydrogen bond interactions are present, as witnessed by IR spectroscopy. The value of the magnetic susceptibility (0.91 B.M.), lower than expected for spinonly $\mathrm{Cu}(\mathrm{II})$ ions (1.73 B.M.), suggests the presence of through-bond interactions among the nearby metal centres along the helices. 
(a)

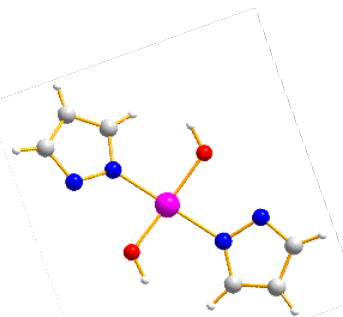

(b)

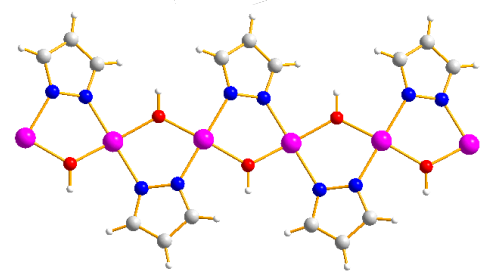

(c)

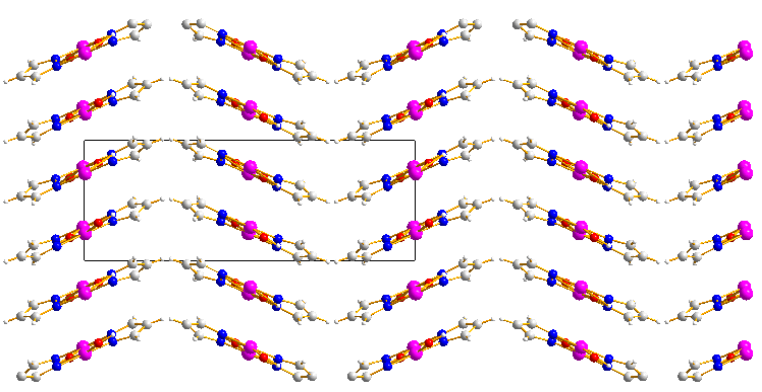

Figure 3. (a) Representation of the trans $-\mathrm{CuN}_{2} \mathrm{O}_{2}$ square planar stereochemistry of the copper(II) ion in 1. (b) Representation of portion of the 1-D helix of collinear metal ions running along the [010] crystallographic direction in 1. (c) Representation of portion of the crystal packing of $\mathbf{1}$ viewed along the [010] crystallographic direction. Horizontal axis, $a$; vertical axis $c$. Colour code: Carbon, grey; hydrogen, light grey; copper, fuchsia; nitrogen, blue; oxygen, red. Main bond distances $(\AA)$ and angles $\left(^{\circ}\right)$ at the metal ion: $\mathrm{Cu}-\mathrm{N} 1.983(16), 2.0469(94)$; Cu-O 1.8831(86), 1.9563(88); intra-chain $\mathrm{Cu} \cdots \mathrm{Cu} 3.386(3)$; N-Cu-N 178.94(55); O-Cu-O 168.86(18); N-Cu-O, 87.88(39), 92.93(41).

Compounds $\mathbf{2}_{\mathrm{DMF}}-\mathbf{4}_{\mathrm{DMF}}$ crystallize in the orthorhombic space group Pnam and are isomorphous. In light of this, their structural features will be described jointly in the following. The asymmetric unit contains half of a copper(II) ion (on an inversion centre, $b$ Wyckoff letter), two halves of two ligands and half of a DMF molecule (on ..m positions, $c$ Wyckoff letter). The metal ions show a trans $-\mathrm{N}_{4} \mathrm{O}_{2}$ octahedral stereochemistry, defined by the nitrogen atoms of four pyrazolate ligands and the oxygen atoms of two solvent molecules (Figures 4a, S5a and S6a; see the captions to the Figures for the main bond distances and angles at the metal ion). In all the compounds, a Jahn-Teller type distortion elongates the $\mathrm{Cu}-\mathrm{O}$ bond distances [2.656(7)-2.780(13) $\AA$ ] with respect to the $\mathrm{Cu}-\mathrm{N}$ ones [1.782(9)-1.999(6) $\AA$ ]. The two independent pz or 4-Xpz spacers (X $=\mathrm{Cl}, \mathrm{Br})$ and the DMF molecules are exo-bidentate, bridging the metal ions along 1-D helices running along the [001] crystallographic direction with a pitch amounting to the value of the $c$-axis (Figures 4b, S5b and S6b). The observed values of the magnetic susceptibility (1.31-1.56 B.M.), which are lower than expected for spin-only $\mathrm{Cu}(\mathrm{II})$ ions, are consistent with the formation of coordination polymers showing through-bond interactions among the neighbouring metal centres. The elongation direction of the helices is consistent with the observed preferred orientation pole ([110]), as inter-helix non-bonding interactions are at work in the $a b$-plane. Indeed, the samples of 
$\mathbf{2}_{\text {DMF }}$ are characterized by thin needles (Figure S7). While in $\mathbf{3}_{\text {DMF }}$ and $\mathbf{4}_{\text {DMF }}$ the copper(II) ion is almost coplanar with the two independent ligands [distance among copper(II) and the r.m.s. planes defined by the penta-atomic rings: 0 and $0.25 \AA$ in $\mathbf{3}_{\mathbf{D M F}}, 0.02$ and $0.25 \AA$ in $\mathbf{4}_{\mathbf{D M F}}$, in $\mathbf{2}_{\mathbf{D M F}}$ the metal centre is almost coplanar with only one of the two spacers [distance among copper and the r.m.s. planes defined by the penta-atomic rings 0.13 and $0.86 \AA]$. The reciprocal disposition of the helices in the $a b$-plane defines a rhombic motif (Figures 4c, S5c and S6c) with an edge amounting to half of the diagonal of the $C$-face of the unit cell. No hydrogen bond interactions are present.

(a)

(b)
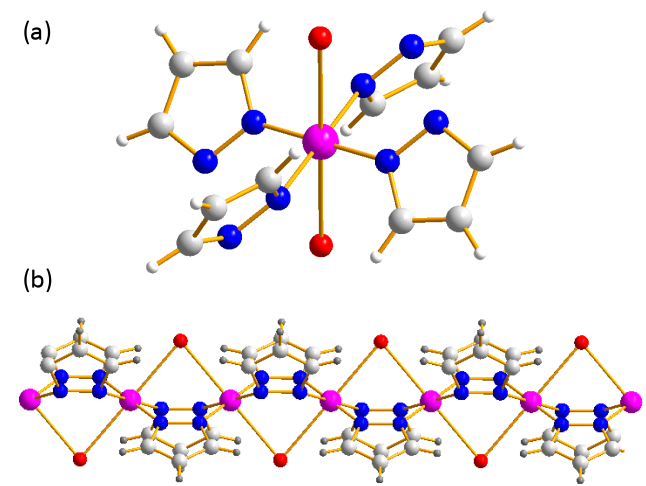

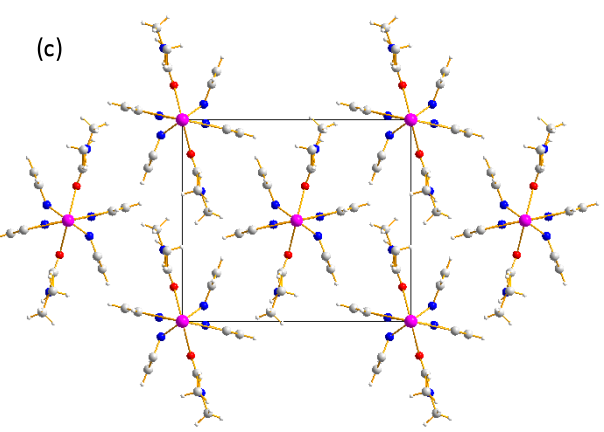

Figure 4. (a) Representation of the trans $-\mathrm{CuN}_{4} \mathrm{O}_{2}$ octahedral stereochemistry of the copper(II) ion in $\mathbf{2}_{\text {DMF. }}$ (b) Representation of portion of the 1-D helix of collinear metal ions running along the [001] crystallographic direction in $\mathbf{2}_{\text {DMF. }}$ (c) Representation of portion of the crystal packing of $\mathbf{2}_{\text {DMF }}$ viewed along the [001] crystallographic direction. oxygen, red. Main bond distances and angles at the metal ion: $\mathrm{Cu}-\mathrm{N}$ 1.782(9), 1.927(14); Cu-O 2.780(13); intra-chain $\mathrm{Cu} \cdots \mathrm{Cu}$ 3.5500(2); N-Cu-N 83.45(62), 96.55(62), 180; O-Cu-O 180; N-Cu-O 81.63(45)-98.37(45). For the representation of the crystal structures of $\mathbf{3}_{\mathrm{DMF}}$ and $\mathbf{4}_{\mathrm{DMF}}$ the reader is referred to Figures S5 and S6.

As expected, upon increasing the van der Waals radius of the atom in position 4 of the pyrazolate ring, the $a$ - and $b$-axis (hence the diagonal of the $C$-face) and the unit cell volume increase proportionally (Table S1 and Figure S8).

As synthesized $\mathbf{5}_{\text {DMF }}\left(\mathbf{m}-\mathbf{5}_{\text {DMF }}\right)$ is characterized by a PXRD pattern which can be indexed by a monoclinic $P$ unit cell [space group $P 112_{1} / m ;{ }^{[[]} a=11.1475(5) \AA, b=9.5458(4) \AA, c=7.3608(2)$ $\left.\AA, \gamma=114.5194(19)^{\circ}, V=712.64(5) \AA^{3}\right]$ describing all the observed Bragg reflections (Figure S9). The unit cell volume is compatible with the formula unit $\left[\mathrm{Cu}(\mu-4-\mathrm{Ipz})_{2}(\mu-\mathrm{DMF})\right]_{\mathrm{n}}$. As proved by PXRD monitoring (Figure S10), this monoclinic phase progressively transforms into an orthorhombic $\mathrm{Cmcm}$ phase, $\mathbf{0 C}-\mathbf{5}_{\mathbf{D M F}}\left(\mathrm{Cmcm}\right.$ is a proper super-group of $\left.P 112_{1} / \mathrm{m}\right)$, which is stable indefinitely. The transformation is completed in about 3.5 hours. This occurrence prevented the structural characterization of the monoclinic phase. In the crystal structure of $\mathbf{0 C}-\mathbf{5}_{\mathbf{D M F}}$, the 
asymmetric unit comprises one quarter of the metal ion (on a $2 / m$ position, $b$ Wyckoff letter), half of a ligand (on a ..m position, $g$ Wyckoff letter) and one quarter of a DMF molecule (on a $m 2 m$ position, $c$ Wyckoff letter). As in compounds $\mathbf{2}_{\mathbf{D M F}}-\mathbf{4}_{\mathbf{D M F}}$, also in $\mathbf{5}_{\mathrm{DMF}}$ the metal ion shows the trans $-\mathrm{CuN}_{4} \mathrm{O}_{2}$ octahedral coordination geometry, defined by the nitrogen atoms of four ligands and the oxygen atom of two solvent molecules (Figure 5a; the Figure caption provides the main bond distances and angles at the metal ion). A Jahn-Teller type distortion involving the $\mathrm{Cu}-\mathrm{O}$ bonds [2.483(2) $\AA$ vs. 1.924(1) $\AA$ of the $\mathrm{Cu}-\mathrm{N}$ bonds] is present. The metal ion is out of the r.m.s. plane defining the penta-atomic ring by $0.35 \AA$. $\mu$-bridging by the ligands and the DMF molecules likewise brings about the formation of 1-D helices running along the $2_{1}$ screw axes parallel to the [001] crystallographic direction (Figure 5b), with a $\mathrm{Cu} \cdots \mathrm{Cu}$ distance of 3.6793(1) $\AA$ (half of the value of the $c$-axis). Similarly, the elongation direction of the 1-D polymeric motifs is consistent with the observed preferred orientation pole ([100]). The helices pack, eclipsed, forming a rhombic motif, with diagonals defined by the $a$ - and $b$-axis (Figure $5 \mathrm{c}$ ).

(a)

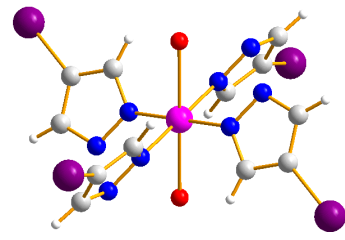

(b)

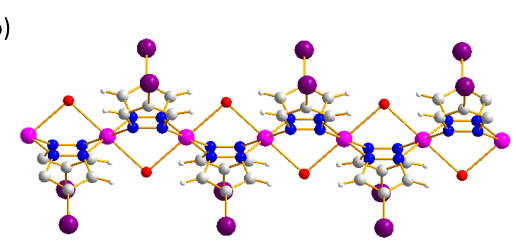

(c)

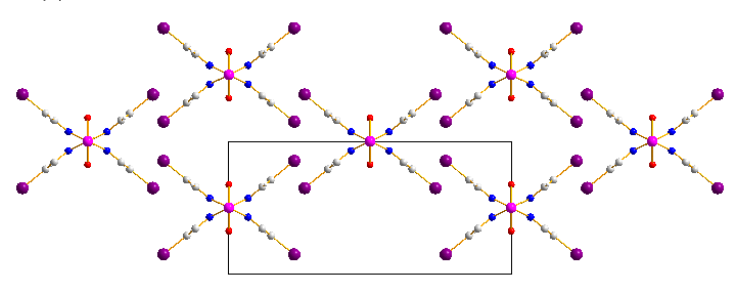

Figure 5. (a) Representation of the trans- $\mathrm{CuN}_{4} \mathrm{O}_{2}$ octahedral stereochemistry of the copper(II) ion in $\mathbf{5}_{\text {DMF }}$. (b) Representation of portion of the 1-D helix of collinear metal ions running along the [001] crystallographic direction in

Horizontal axis, $a$; vertical axis $b$. For clarity, only the oxygen atom of DMF is represented. Colour code: Carbon, grey; hydrogen, light grey; copper, fuchsia; iodine, violet; nitrogen, blue; oxygen, red. Main bond distances $(\AA)$ and angles $\left({ }^{\circ}\right)$ at the metal ion: $\mathrm{Cu}-\mathrm{N}$ 1.924(1); $\mathrm{Cu}-\mathrm{O} 2.483(2)$; intra-chain $\mathrm{Cu} \cdots \mathrm{Cu} 3.6793(1)$; N-Cu-N 180; O-Cu-O 180; N-Cu-O 77.97(34)-102.03(34).

In $\mathbf{5}_{\mathrm{DMF}}$, neither the edges of the rhombi nor the unit cell volume (Table S1) follow the same trend of compounds $\mathbf{2}_{\mathbf{D M F}} \mathbf{4}_{\mathbf{D M F}} v s$. the van der Waals radii of the atom in position 4 of the pyrazolate ring. Indeed, the atomic packing factor of $\mathbf{5}_{\mathrm{DMF}}$ is comparable to that of $\mathbf{3}_{\mathrm{DMF}}$ (Table $\mathrm{S} 1$ ). 


\subsection{Thermal behaviour}

The thermal behaviour of compounds $\mathbf{1}, \mathbf{2}_{\mathbf{D M F}}-\mathbf{5}_{\mathrm{DMF}}$ was investigated by thermogravimetric analysis (TGA) and variable-temperature PXRD. According to the TGA trace (Figure 6a, Scheme 4), under nitrogen 1 is stable up to $503 \mathrm{~K}$. The weight loss of $14.0 \%$ in the temperature range 503 $533 \mathrm{~K}$ can be tentatively ascribed to the loss of one hydroxyl group per formula unit (calculated weight $11.0 \%$ ), leading to the formation of $[\mathrm{Cu}(\mu-\mathrm{pz})]_{\mathrm{n}}$. Decomposition starts immediately after this event. At $1173 \mathrm{~K}$, the residual mass of $40.4 \%$ can be ascribed to metallic copper (calculated residual mass 43.0\%). The VT-PXRD experiment carried out in air (Figure 6b) highlights that 1 decomposes, without prior transformations, in the range $\sim 563-583 \mathrm{~K}$.

According to its TGA trace (Figure S11a, Scheme 4), compound $\mathbf{2}_{\text {DMF }}$ first undergoes a weight loss of $26.2 \%$, which can be interpreted as the loss of one mole of DMF per formula unit (calculated weight loss $26.9 \%$ ), to yield the non-solvated form 2 . After this event, starting from 523 $\mathrm{K}$, a weight loss of $51.0 \%$ is observed, corresponding to the loss of two ligands per formula unit (calculated weight loss 52.2\%).

As evident from their TGA traces (Figures S12a-S14a), compounds $\mathbf{3}_{\mathbf{D M F}}-\mathbf{5}_{\mathbf{D M F}}$ overall undergo the same sequence of transformations, namely (Scheme 4): $i$ ) complete loss of DMF to yield the non-solvated forms 3-5, respectively; ii) loss of one mole of ligand per formula unit, affording the corresponding $[\mathrm{Cu}(\mu-4-\mathrm{Xpz})](\mathrm{X}=\mathrm{Cl}, \mathrm{Br}, \mathrm{I})$ copper(I) compounds; iii) decomposition. Details on these transformations are provided in Table 1.

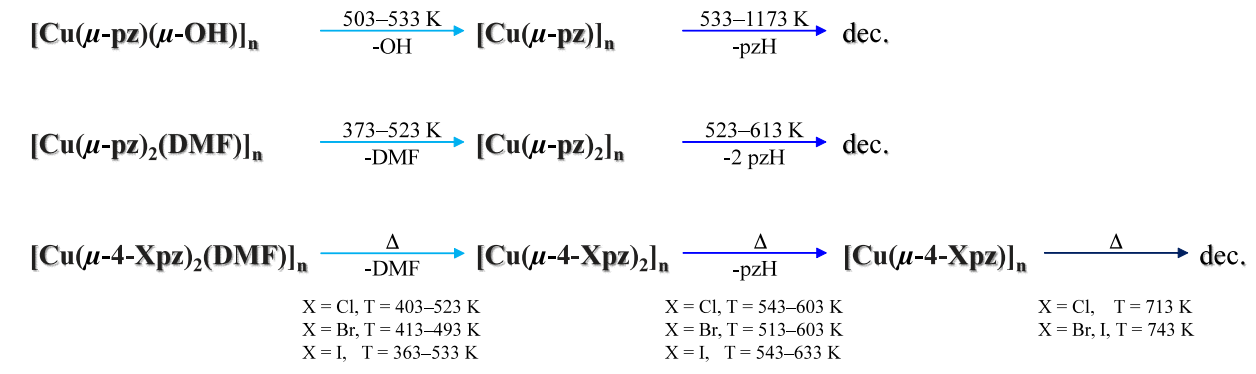

Scheme 4. Thermal behaviour of compounds 1 and $\mathbf{2}_{\mathrm{DMF}}-\mathbf{5}_{\mathrm{DMF}}$, as observed by TGA under a flow of $\mathrm{N}_{2}$. 
Table 1. Details of the thermal behaviour of compounds $\mathbf{2}_{\mathrm{DMF}}-\mathbf{5}_{\mathrm{DMF}}$, as observed by TGA.

\begin{tabular}{llllll}
\hline & & $\mathbf{2}_{\text {DMF }}$ & $\mathbf{3}_{\text {DMF }}$ & $\mathbf{4}_{\text {DMF }}$ & $\mathbf{5}_{\text {DMF }}$ \\
\hline Loss of 1 mol of & T range (K) & $373-523$ & $403-523$ & $413-493$ & $363-533$ \\
solvent per f.u. & Obs.(Calc.) wt. (\%) & $26.2(26.9)$ & $21.6(21.5)$ & $17.9(17.1)$ & $14.4(14.0)$ \\
\hline Loss of 1 mol of & T range (K) & $523-613$ & $543-603$ & $513-603$ & $543-633$ \\
ligand per f.u. & Obs.(Calc.) wt. (\%) & $51.0(52.2)^{\mathrm{a}}$ & $31.3(30.0)$ & $32.6(34.0)$ & $35.6(36.9)$ \\
\hline \multirow{2}{*}{ Decomposition } & Onset T [K] & 673 & 713 & 743 & 743 \\
& Residual mass (\%) & 9.2 & 19.8 & 13.0 & 20.0
\end{tabular}

a In this case, the weight loss can be ascribed to the evolution of two moles of ligand per formula unit.

(a)

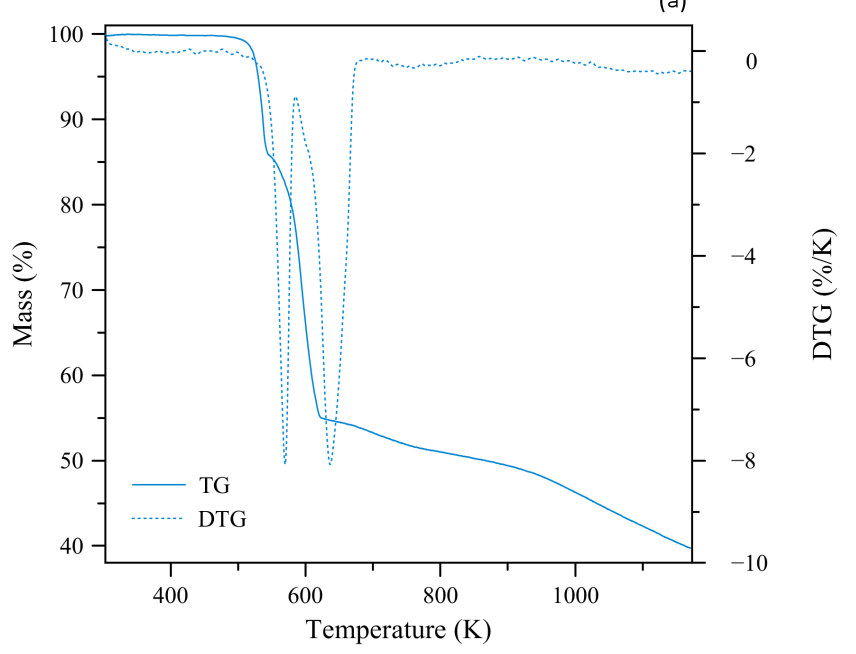

(b)

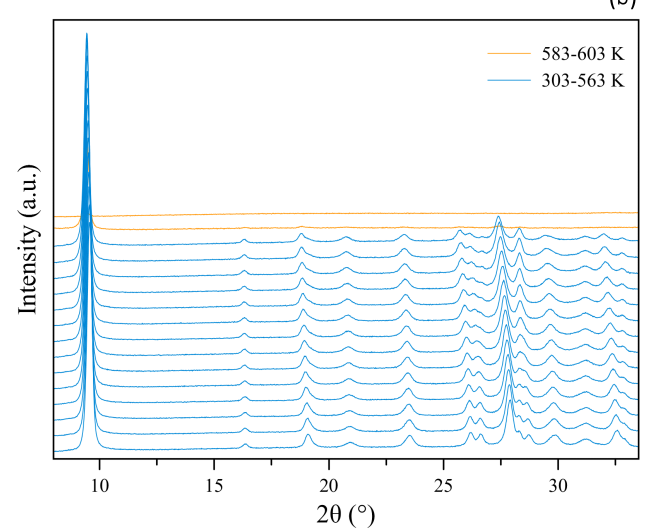

Figure 6. (a) TGA (blue continuous line) trace measured under a flow of $\mathrm{N}_{2}$ on $\mathbf{1}$ and the corresponding DTG trace (blue dashed line). (b) Powder X-ray diffraction patterns acquired on $\mathbf{1}$ as a function of the temperature in the temperature range $303-603 \mathrm{~K}$, with steps of $20 \mathrm{~K}$. 
The VT-PXRD experiment carried out on $\mathbf{2}_{\mathbf{D M F}}$ (Figure S11b) shows the stability of this phase up to $\sim 343 \mathrm{~K}$. At $\sim 363 \mathrm{~K}$ a new phase appears and coexists with $\mathbf{2}_{\mathrm{DMF}}$ up to $523 \mathrm{~K}$, imparting a beige colour to the sample. At $\sim 543 \mathrm{~K}$ a new phase is observed, characterized by only one peak at $\sim 8.4^{\circ}(2 \theta)$, not ascribable to the already known phases $\alpha-\mathrm{Cu}(\mathrm{pz})_{2}$ or $\beta-\mathrm{Cu}(\mathrm{pz})_{2}{ }^{47}$ and disappearing at $663 \mathrm{~K}$. In accordance with what disclosed by TGA, the VT-PXRD data acquired on $\mathbf{3}_{\text {DMF }}$ (Figure $\mathrm{S} 12 \mathrm{~b}$ ) show that the compound is stable up to $\sim 383 \mathrm{~K}$. At $\sim 403 \mathrm{~K}$ a new phase appears and coexists with $3_{\mathrm{DMF}}$ up to $\sim 463 \mathrm{~K}$, imparting a light green colour to the sample. At $\sim 483 \mathrm{~K}$ the green $\alpha$ $\left[\mathrm{Cu}(\mu-4-\mathrm{Clpz})_{2}\right]_{\mathrm{n}}$ polymorph ${ }^{48}$ is formed, which starts loosing crystallinity at $\sim 583 \mathrm{~K}\left(v s . \mathrm{T}_{\mathrm{dec}}=663\right.$ K). ${ }^{48}$ The VT-PXRD experiment carried out on $\mathbf{4}_{\mathbf{D M F}}$ (Figure S13b) unveils that the compound is stable up to $\sim 423 \mathrm{~K}$. At $\sim 443 \mathrm{~K}$ a new low-crystallinity phase of beige colour appears which, based on the TGA, can be interpreted as the non-solvated form 4 . The latter coexists with $\mathbf{4}_{\text {DMF }}$ up to $\sim 463$ $\mathrm{K}$. The powder pattern of 4 cannot be described by the unit cell parameters of the green $[\mathrm{Cu}(\mu-4-$ Brpz) $\left.{ }_{2}\right]_{\mathrm{n}}$ polymorph. ${ }^{48}$ At $\sim 583 \mathrm{~K}$, concomitant to the decomposition of $4, \mathrm{CuBr}_{2}$ is formed (PXRD evidence, acquiring data in the $25.5-86.5^{\circ} 2 \theta$ range). Finally, the VT-PXRD experiment carried out on the orthorhombic $C$ phase $\mathbf{0 C - 5}$-5MF (Figure S14b) highlights that it is stable up to $343 \mathrm{~K}$. At $\sim 363 \mathrm{~K}$ a light-purple phase appears (oP-5 $\mathbf{D M F}$ ), which is stable up to $\sim 483 \mathrm{~K}$ and is sufficiently crystalline to allow for the unit cell parameters retrieval. The obtained orthorhombic space group, Pbnm, is a proper subgroup of $\mathrm{Cmcm}$. The unit cell parameters (Table S1) are comparable to those of the orthorhombic $C$ phase. The colour change and symmetry decrease can be attributed to a partial loss of solvent, as witnessed by the structure determination (see below). At $\sim 503 \mathrm{~K} \mathbf{0 P}-\mathbf{5}_{\mathbf{D M F}}$ greatly loses crystallinity and a new low-crystallinity, light brown phase is formed (5), which is stable up to $\sim 583 \mathrm{~K}$. At $603 \mathrm{~K}$, a peak at $\sim 25.1^{\circ}$ appears, which belongs to $\mathrm{CuI}$ (PXRD evidence, acquiring data in the $23.5-86.5^{\circ} 2 \theta$ range). A schematic representation of the behaviour of $\mathbf{2}_{\mathbf{D M F}^{-}}$ $\mathbf{5}_{\text {DMF }}$ as observed by VT-PXRD is shown in Scheme 5. By comparing the information provided by Schemes 4 and 5, it appears evident that all the coordination polymers show, under nitrogen, a behaviour different than in air.

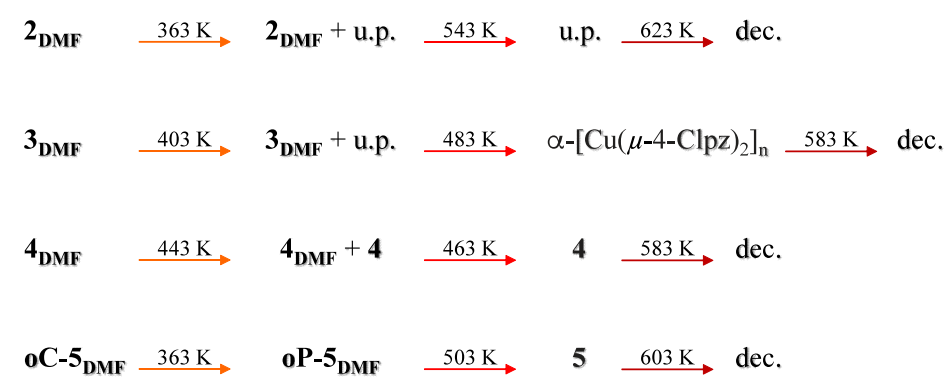


In the crystal structure of $\mathbf{0 P - 5} \mathbf{5}_{\mathbf{D M F}}$, (Figure S15), the asymmetric unit contains half of a $\mathrm{Cu}(\mathrm{II})$ ion (on an inversion centre, Wyckoff letter a), the halves of two ligands and half of a DMF molecule (on ..m positions, Wyckoff letter $c$ ). The mono-dimensional helices composed by the two $\mu-\kappa \mathrm{N}: \kappa N^{\prime}-$ pyrazolate ligands and the $\mu-\kappa \mathrm{O}: \kappa \mathrm{O}-\mathrm{DMF}$ molecule run along the [001] crystallographic direction $[\mathrm{Cu} \cdots \mathrm{Cu}$ distance of about 3.6456(1) $\AA$, half of the $c$ axis]. These chains pack staggered, defining a rhombic motif having the $a$ and $b$ axes as diagonals. The apparent overlap, along the $c$ axis, of different DMF molecules belonging to different chains, can be explained considering that the phase is only partially solvated, as can be seen from the value of 0.5 of the site occupation factor of DMF.

\subsection{Electronic state transition spectroscopy}

UV-Vis-NIR absorption and fluorescence emission spectroscopy measurements were performed in order to shed some light on the local-level structural features of the species $\mathbf{2 , 4}$ and $\mathbf{5}$, obtained upon heating $\mathbf{2}_{\mathbf{D M F}}, \mathbf{4}_{\mathrm{DMF}}$ and $\mathbf{5}_{\mathrm{DMF}}$ and preliminary interpreted as non-solvated $[\mathrm{Cu}(\mu-$ $\left.\mathrm{pz})_{2}\right]_{\mathrm{n}}$ and $\left[\mathrm{Cu}(\mu-4-\mathrm{Xpz})_{2}\right]_{\mathrm{n}}(\mathrm{X}=\mathrm{Br}, \mathrm{I})$ compounds, the too low crystallinity of which prevented a structural determination from PXRD data. As anticipated above, the crystal structure of $\alpha-[\mathrm{Cu}(\mu-4-$ $\left.\mathrm{Clpz})_{2}\right]_{\mathrm{n}}$, compound $\mathbf{3}$ in the present work, was reported by Storr and co-workers as early as in $1991,{ }^{48}$ and consisted in 1-D helices with $\mathrm{CuN}_{4}$ tetrahedral metal centres. Hence, we used $\mathbf{3}$ as a benchmark for the assessment of the tetrahedral stereochemistry spectral properties, as compared to $\mathbf{3}_{\mathbf{D M F}}$, which was used to typify the octahedral geometry. In Figure $7 \mathrm{a}$ the absorption spectra of $\mathbf{3}_{\mathbf{D M F}}$ and $\mathbf{3}$ in the $200-1200 \mathrm{~nm}$ spectral band are shown. The UV portion of the $\mathbf{3}_{\mathbf{D M F}}$ spectrum is dominated by two major bands, one peaked at $210 \mathrm{~nm}$, which can be attributed to the pyrazolate chromophore $\pi-\pi^{*}$ transition, the other one peaked at $330 \mathrm{~nm}$, which we ascribe to a charge-transfer transition from the pyrazolate ligand to the $\mathrm{Cu}(\mathrm{II})$ metal ions. In the visible region, the $\mathrm{Cu}(\mathrm{II}) d-d$ transitions ( $\mathrm{se}^{48}$ for the attribution) build up a broad band peaked at $550 \mathrm{~nm}$, with a shoulder in the red, around $650 \mathrm{~nm}$. The same transitions can be detected in the spectrum of $\mathbf{3}$. However, they are all notably red-shifted (to $240 \mathrm{~nm}, 380 \mathrm{~nm}$, and $630 \mathrm{~nm}$, respectively), with the $d$ - $d$ transition band shoulder falling in the NIR, around $800 \mathrm{~nm}$, in agreement with results previously reported by Storr. ${ }^{48}$ This evidence suggests a completely different charge distribution in the octahedral versus tetrahedral geometry.

In Figure $7 \mathrm{~b}$, the fluorescence emission spectra obtained upon excitation of $\mathbf{3}_{\mathrm{DMF}}$ and $\mathbf{3}$ at the respective $\pi-\pi^{*}$ transition band peak are shown. While the former spectrum consists in a broad, 
almost unstructured main band covering the 400-480 nm wavelength interval, and in a second, less intense band peaked at $545 \mathrm{~nm}$, the latter spectrum is constituted by three well defined bands peaked at $400 \mathrm{~nm}, 480 \mathrm{~nm}$ and $535 \mathrm{~nm}$, respectively. Moreover, the green fluorescence band is relatively more intense than the blue fluorescence band in the $\mathbf{3}$ than in the $\mathbf{3}_{\text {DMF }}$ spectrum. In Figure 7c, the fluorescence spectra obtained upon excitation of $\mathbf{3}_{\mathrm{DMF}}$ and $\mathbf{3}$ at the respective chargetransfer transition band peak are displayed. While the former complex emits sizeable fluorescence peaked at $435 \mathrm{~nm}$, the latter is almost non-fluorescent. In light of this, the observations made on the fluorescence spectral features upon excitation at the $\pi-\pi^{*}$ transition band peak can be given an interpretation. Indeed, the continuous emission from $400 \mathrm{~nm}$ to $480 \mathrm{~nm}$ in $\mathbf{3}_{\text {DMF }}$ can be interpreted as the result of the emission bands peaked at $400 \mathrm{~nm}$ and $480 \mathrm{~nm}$, detected also for $\mathbf{3}$, superimposed with the emission band peaked at $435 \mathrm{~nm}$ due to out-of-peak excitation of the charge-transfer transition. In summary, desolvation of $\mathbf{3}_{\mathbf{D M F}}$, resulting in a change from an octahedral to a tetrahedral geometry of the metal ion, implies a general bathochromic shift of the UV-Vis absorption bands, combined to a substantial quenching of fluorescence emission, associated to the relaxation from the charge-transfer transition state.
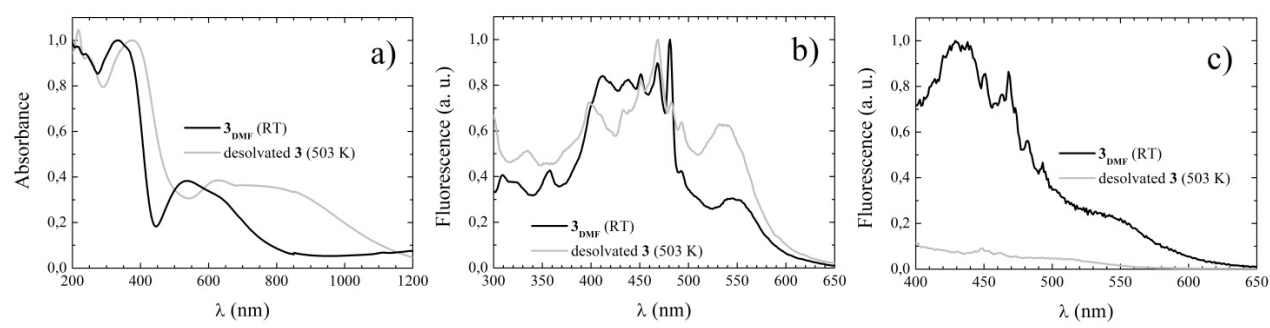

Figure 7. Comparison of the electronic-state transition spectroscopic properties of $\mathbf{3}_{\mathrm{DMF}}$ and $\mathbf{3}$ : a) UV-Vis-NIR absorption spectra; b) fluorescence emission spectra upon excitation at the $\pi-\pi *$ transition band peak; c) fluorescence emission spectra upon excitation at the charge-transfer band peak. Colour codes are specified in the figure legends.

The above described spectral properties were used as benchmarks of the presence of the tetrahedral geometry in the powders of $\mathbf{2}, \mathbf{4}$, and $\mathbf{5}$. Upon heating a sample of $\mathbf{2}_{\mathrm{DMF}}$ at $463 \mathrm{~K}$, a new phase appears and is present together with $\mathbf{2}_{\mathbf{D M F}}$ (Figure S11): the absorption and fluorescence spectral features of $\mathbf{2}_{\mathbf{D M F}}$ are conserved in this sample (see Figure 8 ), although we assist to both a widening of the absorption bands, and a partial quenching of the charge-transfer transition excited fluorescence, possibly due to local distortions. Heating to $583 \mathrm{~K}$, temperature at which $\mathbf{2}_{\mathrm{DMF}}$ has completely disappeared (Figure S11), results in complete loss of the absorption spectral line-shape structure (Figure $8 \mathrm{a}$ ). Namely, the $\pi-\pi^{*}$ charge transfer and $d-d$ transition lines are integrated within a rather broad absorption band peaked at $355 \mathrm{~nm}$. Thus, although a red shift in the main absorption 
peak is actually observed, a convincing evidence in favour of the assumption of the tetrahedral geometry is lacking. Nonetheless, upon excitation at $355 \mathrm{~nm}$, no fluorescence signal is detected (Figure 8c). Moreover, upon excitation at $240 \mathrm{~nm}$, a fluorescence spectrum very similar to that observed for $\mathbf{3}$ is retrieved (Figure $8 b$ ).
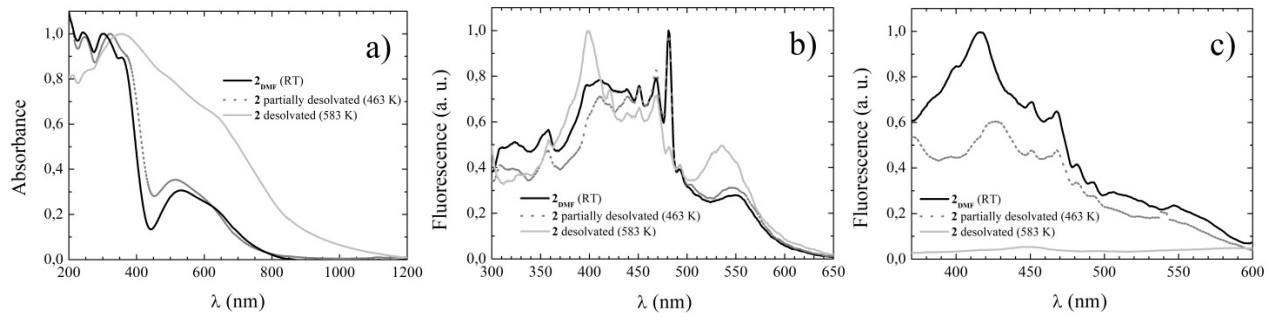

Figure 8. Comparison of the electronic-state transition spectroscopic properties of $\mathbf{2}_{\mathrm{DMF}}, \mathbf{2}_{\mathrm{DMF}}$ heated at $463 \mathrm{~K}$, and $\mathbf{2}$ : a) UV-Vis-NIR absorption spectra; b) fluorescence emission spectra upon excitation at the $\pi-\pi^{*}$ transition band peak; c) fluorescence emission spectra upon excitation at the charge-transfer band peak. Colour codes are specified in the figure legends.

The situation is more suggestive in the case of $\mathbf{4}_{\mathbf{D M F}}$ heated to $643 \mathrm{~K}$ (Figure 9) and $\mathbf{5}_{\mathbf{D M F}}$ heated to $523 \mathrm{~K}$ (Figure 10), temperatures at which the low crystallinity phases $\mathbf{4}$ and $\mathbf{5}$ are detected by VT-PXRD (Figures S13 and S14, respectively).
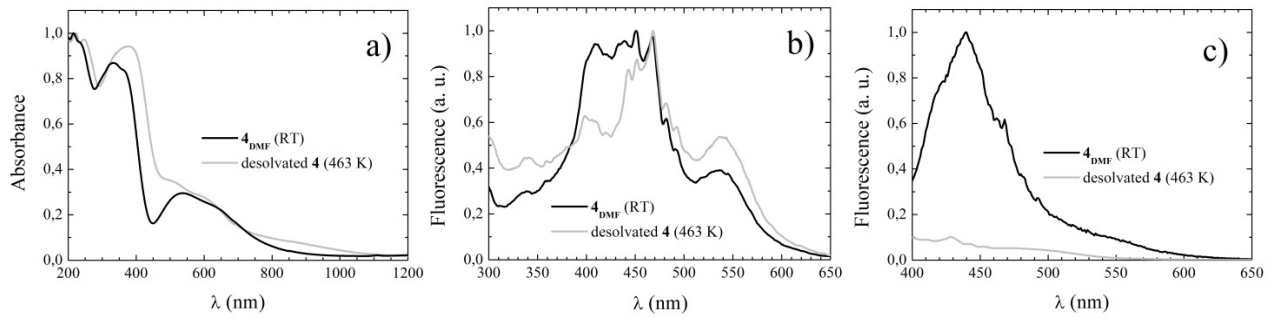

Figure 9. Comparison of the electronic-state transition spectroscopic properties of $\mathbf{4}_{\mathrm{DMF}}$ and 4 : a) UV-Vis-NIR absorption spectra; b) fluorescence emission spectra upon excitation at the $\pi-\pi^{*}$ transition band peak; c) fluorescence emission spectra upon excitation at the charge-transfer band peak. Colour codes are specified in the figure legends.

In these cases, both the $\pi-\pi^{*}$ and the charge transfer bands are well resolvable within the absorption spectrum, and they are both significantly red shifted with respect to $\mathbf{4}_{\mathbf{D M F}}$ (Figure 9a) and $5_{\text {DMF }}$ (Figure 10a). Moreover, the shoulder above $800 \mathrm{~nm}$ distinctive of the $d$ - $d$ absorption of tetrahedral $\mathrm{Cu}$ (II) ions in $\mathbf{3}$ appears, although in the case of $\mathbf{4}$ also a blue-shifted $d$ - $d$ absorption is present. The fluorescence spectra of both 4 (Figure 9b) and 5 (Figure 10b) obtained upon excitation at the $\pi-\pi^{*}$ band peak display the characteristic two-bands shape of $\mathbf{3}$, and a minimum in correspondence of the fluorescence emission maximum detected upon excitation of the solvated 
compounds at the charge-transfer band peak. Moreover, excitation in this band does not result in fluorescence emission for either of the two compounds (Figures $9 \mathrm{c}$ and 10c).
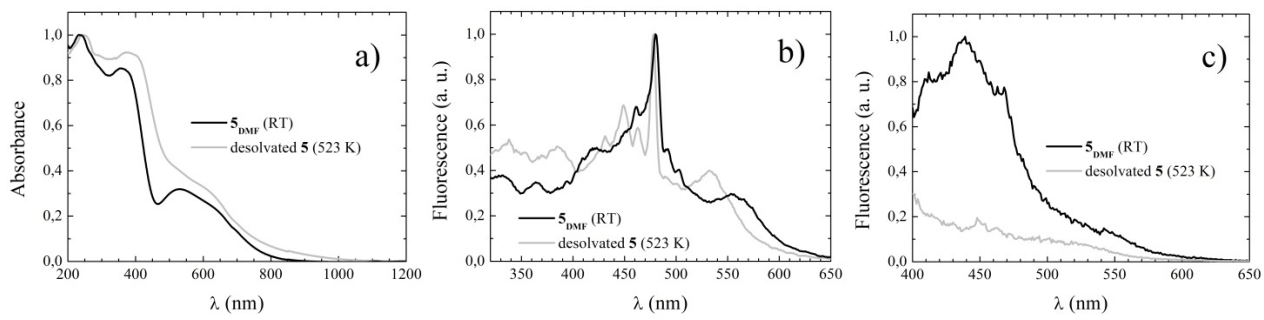

Figure 10. Comparison of the electronic-state transition spectroscopic properties of $\mathbf{5}_{\mathrm{DMF}}$ and 5: a) UV-Vis-NIR absorption spectra; b) fluorescence emission spectra upon excitation at the $\pi-\pi^{*}$ transition band peak; c) fluorescence emission spectra upon excitation at the charge-transfer band peak. Colour codes are specified in the figure legends.

These spectral features concur in indicating that the metal centre of the non-solvated complexes assumes a tetrahedral geometry, although the appearance of a blue-shifted $d$ - $d$ band and the lower intensity of the $800 \mathrm{~nm} d$-d shoulder with respect to 3 might be the symptom of partial loss of crystallinity. The main spectroscopic data just discussed are compared in Table 2. 
Table 2. Spectral properties of $\mathbf{2}_{\mathrm{DMF}}-\mathbf{5}_{\mathrm{DMF}}$ and 2-5. Peak wavelength of $\pi-\pi^{*}$ transition absorption band, $\boldsymbol{\lambda}_{\mathrm{a}-\mathrm{i}}$; peak wavelength of charge-transfer transition absorption band, $\lambda_{\text {charge}}$; peak wavelength of $d$ - $d$ transition absorption band, $\lambda_{\mathrm{d}-}$ d; peak wavelength(s) of fluorescence emission spectrum upon excitation at the $\pi-\pi^{*}$ transition band peak, $\lambda_{\text {fluo, }}$; peak wavelength of fluorescence emission spectrum upon excitation at the charge-transfer transition band peak, $\lambda_{\text {fluo,charge }}$.

\begin{tabular}{|c|c|c|c|c|c|}
\hline Compound & $\lambda_{\pi=\pi}(\mathbf{n m})$ & $\lambda_{\text {charge }}(\mathrm{nm})$ & $\lambda_{\mathrm{d}-\mathrm{d}}(\mathrm{nm})$ & $\lambda_{\text {fluo }, \cdots x-\infty}(\mathrm{nm})$ & $\lambda_{\text {fluo,charge }}(\mathrm{nm})$ \\
\hline $2_{\text {DMF }}$ & 242 & 300 & $531(621)$ & $\begin{array}{l}411,439,451, \\
468,481,547\end{array}$ & 417 \\
\hline 2 & (259) & 355 & $(620)$ & $398,469,535$ & - \\
\hline $3_{\text {DMF }}$ & $213(238)$ & 332 & $536(625)$ & $\begin{array}{l}412,437,451, \\
468,481,545\end{array}$ & 434 \\
\hline 3 & $217(253)$ & 374 & $629(800)$ & $400,468,536$ & - \\
\hline $4_{\mathrm{DMF}}$ & $215(232)$ & 332 & $535(620)$ & $\begin{array}{l}411,439,451, \\
468,536\end{array}$ & 439 \\
\hline 4 & 223,245 & 375 & $500(590,840)$ & $403,468,540$ & - \\
\hline $5_{\mathrm{DMF}}$ & 236 & 357 & $528(628)$ & $\begin{array}{l}420,461,480, \\
554\end{array}$ & 440 \\
\hline 5 & 250 & 370 & $520(605,850)$ & $\begin{array}{l}431,450,463, \\
533\end{array}$ & - \\
\hline
\end{tabular}

\subsection{Theoretical characterization}

The availability of accurate structural parameters has paved the way for the ab initio study of compounds $\mathbf{1}$ and $\mathbf{2}_{\mathrm{DMF}}-\mathbf{5}_{\mathrm{DMF}}$. Starting from the experimental crystal structure, each compound was fully relaxed in both its low- and high-spin configuration. For all compounds, the low-spin configuration is favoured with respect to the high-spin state by a quantity ranging from $1.13\left(\mathbf{2}_{\mathbf{D M F}}\right)$ to $5.69(1) \mathrm{kJ} / \mathrm{mol}$, as evaluated at the B3LYP-D* level. In all the systems, the spin-only magnetic moment has a value of $\sim 1.27$ B.M., in rather good agreement with the observed ones.

The B3LYP-D* equilibrium structures of the compounds (see Tables S2 and S3 for the unit cell parameters) show a sensitive contraction of the unit cell volumes $(\sim-9 \%)$ with respect to the experimental values, which can be ascribed to an overestimation of the dispersive interactions in particular along the $\mathrm{O} \cdots \mathrm{Cu} \cdots \mathrm{O}$ direction, due to Grimme's correction. Nevertheless, in spite of the volume contractions, the mean bond distances and angles are overall preserved. In particular, in $\mathbf{2}_{\mathbf{D M F}}-\mathbf{5}_{\mathbf{D M F}}$ the $\mathrm{Cu} \cdots \mathrm{Cu}$ intra-chain distances have values of $\sim 3.5 \AA$ and the $\mathrm{Cu}-\mathrm{O}$ bonds, which are shorter by $\sim 0.2 \AA$ with respect to the experimental values, are still $20 \%$ longer that the $\mathrm{Cu}-\mathrm{N}$ ones, as predicted by the Jahn-Teller distortion. As regards 1, the $\mathrm{Cu}-\mathrm{O}(1.98-1.99 \AA)$ and $\mathrm{Cu}-\mathrm{N}(1.97-$ $1.99 \AA ̊$ ) distances are almost indistinguishable and extremely closed to the experimental values. 
PBE geometries optimization (see Table S4 for the unit cell parameters) yielded a sensitive increase of the unit cell volumes, confirming the key role of dispersive interactions in determining the crystal structure of these compounds.

The B3LYP-D* optimized geometries were then used to calculate the harmonic IR frequencies, whose wavenumbers are all real, confirming that the periodic models are minima on the potential energy surface. Despite significant discrepancies in the absolute values of calculated $v s$. measured frequencies, due to the well-known difficulties of the harmonic approximation in describing light-atom modes, the main features of the experimental spectra are perfectly reproduced, as well as the general trends and peculiarities of each compound. The IR spectrum of 1 presents the $\mathrm{O}-\mathrm{H}$ bond stretching mode at $3790 \mathrm{~cm}^{-1}$ (vs. the experimental value of $3602 \mathrm{~cm}^{-1}$ ) and confirms the assignment of the signal around $920 \mathrm{~cm}^{-1}$ to the vibration of the $\mathrm{Cu}-\mathrm{O}$ bond. The different coordination of the $\mathrm{Cu}(\mathrm{II})$ metal site in $\mathbf{1}$ and $\mathbf{2}_{\mathrm{DMF}}$ clearly emerges from the spectral fingerprint of the two polymers, as shown in Figure S16. The IR spectra of $\mathbf{2}_{\mathbf{D M F}}-\mathbf{5}_{\mathbf{D M F}}$ exhibit similar patterns, as already pointed out in section 2.1. The presence of coordinated DMF is confirmed by the intense band in the range $1713-1705 \mathrm{~cm}^{-1}$, due to the $\mathrm{C}=\mathrm{O}$ stretching and correctly red-shifted with respect to its calculated position in the free DMF molecule $\left(1775 \mathrm{~cm}^{-1}\right)$. The effect of the halogen atomic mass is highlighted by the calculated $v(\mathrm{C}-\mathrm{X})$ stretching mode frequencies of $\mathbf{3}_{\mathbf{D M F}}-\mathbf{5}_{\mathbf{D M F}}$ that are found at 1008,975 and $959 \mathrm{~cm}^{-1}$ for $\mathrm{X}=\mathrm{Cl}, \mathrm{Br}$ and I, respectively.

The thermal behaviour was simulated by totally removing DMF molecules from $\mathbf{3}_{\mathrm{DMF}} \mathbf{-} \mathbf{5}_{\mathrm{DMF}}$. A subsequent complete relaxation of the structures has led to the theoretical coordination polymers 3-5, whose structural parameters are summarized in Table S5. In all cases, the predictable structural effect is a dramatic reduction of the unit cell volumes that become almost $30 \%$ smaller than in the solvated compounds. From an energetic point of view, the non-solvated structures are 103.6, 115.5 and $164.4 \mathrm{~kJ} / \mathrm{mol}$ less stable than the $\mathbf{3}_{\mathrm{DMF}}, \mathbf{4}_{\mathrm{DMF}}$ and $\mathbf{5}_{\mathrm{DMF}}$ systems, respectively, at the B3LYP-D* level. A similar estimate, performed with B3LYP only, shows that almost the $70 \%$ of the computed stability has to be ascribed to the $\mathrm{Cu}-\mathrm{O}$ bond and that this essential contribution is mainly due to dispersive interactions, slightly overestimated by the a posteriori Grimme-D3 correction. The peaks of the $v(\mathrm{C}-\mathrm{X})$ stretching modes, due to the absence of the DMF molecules, are blue-shifted $\left(\sim 6 \mathrm{~cm}^{-1}\right.$ $v s$. the measured shift of $0-5 \mathrm{~cm}^{-1}$ ) as can be seen in Figure S17. Interestingly enough, calculations indicate that the volume reduction is also driven by the incoming of new interplays involving the $\mathrm{Cu}$ (II) ions. In particular, in the $\mathrm{Cl} / \mathrm{Br}$ compounds the $\mathrm{Cu}-\mathrm{X}(\mathrm{X}=\mathrm{Cl}, \mathrm{Br})$ distances of 5.41/5.37 $\dot{\mathrm{A}}$ in $\mathbf{3}_{\text {DMF }} / \mathbf{4}_{\text {DMF }}$ are shortened to $3.42 / 3.33 \dot{\mathrm{A}}$ in $\mathbf{3} / \mathbf{4}$.

Unfortunately, simulations performed at $0 \mathrm{~K}$ prevent to overcome the local minimum in the potential energy surface represented by the square planar coordination of the metal site: a certain 
amount of thermal energy is indeed needed to promote the concerted rearrangement of the pyrazole rings yielding to the observed tetrahedral coordination of $\mathrm{Cu}(\mathrm{II})$.

\section{Experimental Section}

\subsection{Materials and Methods}

All the chemicals were purchased from Sigma-Aldrich and used without further purification. $\left[\mathrm{Cu}(\mu-\mathrm{pz})_{2} \cdot \mathrm{H}_{2} \mathrm{O}\right]_{\mathrm{n}}{ }^{42}$ and $\left[\mathrm{Cu}_{3}\left(\mu_{3}-\mathrm{OH}\right)(\mu-\mathrm{pz})_{3}\left(\mathrm{CH}_{3} \mathrm{COO}\right)_{2}(\mathrm{pzH})\right]^{27}$ were prepared according to literature methods. All the reactions and manipulations were carried out in air, under either ambient or solvothermal conditions. Elemental analyses $(\mathrm{C}, \mathrm{H}, \mathrm{N})$ were performed with a Fisons Instruments 1108 CHNS-O elemental analyser. Infrared spectra were recorded from 4000 to $650 \mathrm{~cm}^{-1}$ with a Perkin Elmer Spectrum One Model FTIR spectrometer with ATR mode. Thermogravimetric analyses on $\mathbf{2}_{\mathrm{DMF}}-\mathbf{4}_{\mathrm{DMF}}$ and $\mathbf{m}-\mathbf{5}_{\mathrm{DMF}}$ were performed using a Thermogravimetric Analyzer Pyris 1 Perkin-Elmer heating from 303 to $1073 \mathrm{~K}$ with a speed of $10 \mathrm{~K} / \mathrm{min}$, under a flow of $\mathrm{N}_{2}(30$ $\mathrm{mL} / \mathrm{min}$ ). The accuracy of the sample temperature measurement was checked by the onset fusion temperature of indium $(156.6,0.2 \mathrm{~K})$ and tin $(232.0,0.2 \mathrm{~K})$ with heating/cooling dynamic segments. The experiments were repeated twice to confirm the reproducibility of the generated data. Simultaneous thermal analysis (simultaneous thermogravimetric analysis and differential scanning calorimetry) on 1 was carried out using a NETZSCH STA 409 PC instrument. $10 \mathrm{mg}$ of assynthesised 1 were placed in an alumina crucible; the temperature programme ranged from 303 to $1173 \mathrm{~K}$ with a heating rate of $10 \mathrm{~K} \mathrm{~min}^{-1}$ under a flow of $\mathrm{N}_{2}\left(40 \mathrm{~mL} \mathrm{~min}^{-1}\right)$. Raw data from TGA and DSC were corrected based on a background curve. Magnetic susceptibilities were measured at 293 K by the Gouy method with a Sherwood Scientific magnetic balance MSB-Auto, using $\mathrm{HgCo}(\mathrm{NCS})_{4}$ as calibrant, and were corrected for diamagnetism with the appropriate Pascal constants. The magnetic moments (in Bohr Magnetons, B.M.) were calculated from the equation $\mu_{\text {eff }}=2.84\left(\chi_{\mathrm{m}}{ }^{\text {corr }} \mathrm{T}\right)^{1 / 2}$, where $\chi_{\mathrm{m}}{ }^{\text {corr }}$ is the corrected mass magnetic susceptibility, $\mathrm{T}=293 \mathrm{~K}$. The SEM images were acquired with a Field Emission Scanning Electron Microscope (FE-SEM) ZEISS SIGMA 300 FESEM equipped with Gemini column, able to reach a maximum resolution of $1.2 \mathrm{~nm}$, and with three electron detectors, namely: high efficiency secondary "in-lens" electron detector; ETSE secondary electron detector (Everhart-Thornley Secondary Electrons); HDBSD backscattered electron detector with 4 independent sectors (High Definition Back Scattered Detector). Powder Xray diffraction (PXRD) qualitative analyses were carried out with a Bruker D8 Advance diffractometer (see the section describing the structure characterization for the instrument specifics), acquiring data at room temperature in the $3-35^{\circ} 2 \theta$ range, with steps of $0.02^{\circ}$ and time per step of $1 \mathrm{~s}$. 
The electronic-state absorption spectroscopy measurements were undertaken by taking advantage of a Jasco V-770 UV-Vis-NIR spectrophotometer, equipped with a ISN-923 $60 \mathrm{~mm}$ integrating sphere and an explicitly designed solid-state sample holder. The fluorescence emission spectra in solid state were recorded with a Jasco FP 8500 spectrofluorimeter. The powders were introduced in the same sample holder as above and submitted to the excitation beam with an inclination angle of $36^{\circ}$ through a goniometric lodge, in order to minimize collection of excitation stray light.

\subsection{Syntheses}

Synthesis of $[\mathrm{Cu}(\mu-\mathrm{pz})(\mu-\mathrm{OH})]_{n}, \quad$ 1. $[\mathrm{Cu}(\mu-\mathrm{pz})(\mu-\mathrm{OH})]_{\mathrm{n}}$ was isolated by following two synthetic approaches:

a) A suspension of $\left[\mathrm{Cu}_{3}\left(\mu_{3}-\mathrm{OH}\right)(\mu-\mathrm{pz})_{3}\left(\mathrm{CH}_{3} \mathrm{COO}\right)_{2}(\mathrm{pzH})\right](1.0 \mathrm{mmol}, 0.595 \mathrm{~g})$ in water $(100 \mathrm{~mL})$ was refluxed for $3 \mathrm{~h}$, observing a colour change of the solid from blue to blue-violet. The blueviolet solid was filtered, washed with water and dried under vacuum at room temperature, recovering 1 in the form of powders. Yield $0.107 \mathrm{~g}, 72 \%$. Melting point: $>573 \mathrm{~K}$ (decomposition).

Elemental analysis calculated for $\mathrm{C}_{3} \mathrm{H}_{4} \mathrm{CuN}_{2} \mathrm{O}: \mathrm{C}, 24.41, \mathrm{H}, 2.73 ; \mathrm{N}, 18.98 \%$. found: $\mathrm{C}, 24.62$; $\mathrm{H}, 2.68, \mathrm{~N}, 18.85 \%$. IR $\left(\mathrm{cm}^{-1}\right): 3602 \mathrm{~m} v(\mathrm{O}-\mathrm{H}), 3117 \mathrm{w} v\left(\mathrm{C}-\mathrm{H}_{\text {arom }}\right), 1489 \mathrm{~m}, 1415 \mathrm{~m}, 1378 \mathrm{~s}$ $v(\mathrm{C}=\mathrm{C}+\mathrm{C}=\mathrm{N}), 1276 \mathrm{~m}, 1182 \mathrm{~m}, 1061 \mathrm{~s}, 921 \mathrm{~s} v(\mathrm{Cu}-\mathrm{O}), 872 \mathrm{~m}, 748 \mathrm{vs}$. Magnetic susceptibility: $\mu_{\text {eff }}(293 \mathrm{~K})=0.91$ B.M.

b) A suspension of $\left[\mathrm{Cu}(\mu-\mathrm{pz})_{2} \cdot \mathrm{H}_{2} \mathrm{O}\right]_{\mathrm{n}}(1.0 \mathrm{mmol}, 0.217 \mathrm{~g})$ in water $(100 \mathrm{~mL})$ was refluxed for $2 \mathrm{~h}$. The obtained blue-violet solid was quickly filtered, washed with water, dried under vacuum and recognized as $\mathbf{1}$ by means of elemental analysis and infrared spectroscopy. Yield $0.115 \mathrm{~g}$, $78 \%$.

Synthesis of $\left[C u(\mu-p z)_{2}(\mu-D M F)\right]_{n}, 2_{D M F} \cdot \mathrm{Cu}\left(\mathrm{CH}_{3} \mathrm{COO}\right)_{2} \cdot \mathrm{H}_{2} \mathrm{O}(1.0 \mathrm{mmol}, 0.199 \mathrm{~g})$ was added to a $\mathrm{pzH}(2 \mathrm{mmol}, 0.136 \mathrm{~g})$ solution in DMF $(20 \mathrm{~mL})$. The reaction was carried out by the microwave-assisted solvothermal technique with the following reaction conditions: $0.5 \mathrm{~h}$ at $413 \mathrm{~K}$, $2 \mathrm{~h}$ at $393 \mathrm{~K}$ and slow cooling at $8 \mathrm{~K}$ /minute to room temperature. The pale pinkish-violet precipitate thus obtained was filtered, washed with cold DMF and dried in air. Yield $0.223 \mathrm{~g}, 84 \%$. Elemental analysis calculated for $\mathrm{C}_{9} \mathrm{H}_{13} \mathrm{CuN}_{5} \mathrm{O}: \mathrm{C}, 39.92 ; \mathrm{H}, 4.84 ; \mathrm{N}, 25.86 \%$. found: $\mathrm{C}, 39.79 ; \mathrm{H}$, 4.79; N, 25.77\%. IR ( $\left.\mathrm{cm}^{-1}\right): 3129 \mathrm{w}$ and 3106w v(C-H $\left.\mathrm{H}_{\text {arom }}\right), 2927 \mathrm{wbr} v\left(\mathrm{C}-\mathrm{H}_{\text {aliph }}\right), 1655 \mathrm{vs} v(\mathrm{C}=\mathrm{O})$, $1483 \mathrm{~m} v(\mathrm{C}=\mathrm{C}+\mathrm{C}=\mathrm{N}), 1383 \mathrm{~s} 1095 \mathrm{~m}, 1055 \mathrm{~s}, 862 \mathrm{~m}, 745 \mathrm{vs}$. Magnetic susceptibility: $\mu_{\mathrm{eff}}(293 \mathrm{~K})=$ 1.56 B.M.

Synthesis of $\left[C u(\mu-4-C l p z)_{2}(\mu-D M F)\right]_{n}, \quad 3_{\text {DMF }}$. The pale violet compound $\mathbf{3}_{\mathbf{D M F}}$ was synthesized similarly to $\mathbf{2}_{\text {DMF }}$ by using 4-chloro-1H-pyrazole (4-ClpzH) instead of pzH. Yield 0.289 
g, 88\%. Elemental analysis calculated for: $\mathrm{C}_{9} \mathrm{H}_{11} \mathrm{Cl}_{2} \mathrm{CuN}_{5} \mathrm{O}$ : C, 31.82; H, 3.26; N, 20.62\%. Found: C, 31.78; H, 3.13; N, 20.53\%. IR ( $\left.\mathrm{cm}^{-1}\right): 3146 v w v\left(\mathrm{C}-\mathrm{H}_{\text {arom }}\right), 2931$ wbr $v\left(\mathrm{C}-\mathrm{H}_{\text {aliph }}\right), 1655 \mathrm{vs} v(\mathrm{C}=\mathrm{O})$, $1496 \mathrm{~m} v(\mathrm{C}=\mathrm{C}+\mathrm{C}=\mathrm{N}), 1394 \mathrm{~s}, 1099 \mathrm{~m}, 1058 \mathrm{~m}, 969 \mathrm{~s} v(\mathrm{C}-\mathrm{Cl}), 830 \mathrm{~s}, 662 \mathrm{~m}$. Magnetic susceptibility: $\mu_{\text {eff }}(293 \mathrm{~K})=1.32$ B.M.

Synthesis of $\left[C u(\mu-4-B r p z)_{2}(\mu-D M F)\right]_{n}, 4_{\mathbf{D M F}}$. The pale violet compound $\mathbf{4}_{\mathbf{D M F}}$ was synthesized similarly to $\mathbf{2}_{\mathbf{D M F}}$ by using 4-bromo-1H-pyrazole (4-BrpzH) instead of pzH. Yield $0.383 \mathrm{~g}, 89 \%$. Elemental analysis calculated for: $\mathrm{C}_{9} \mathrm{H}_{11} \mathrm{Br}_{2} \mathrm{CuN}_{5} \mathrm{O}: \mathrm{C}, 25.22 ; \mathrm{H}, 2.59 ; \mathrm{N}, 16.34 \%$. Found: C, 25.32; H, 2.57; N, 16.27\%. IR ( $\left.\mathrm{cm}^{-1}\right): 3146 \mathrm{vw} v\left(\mathrm{C}-\mathrm{H}_{\text {arom }}\right), 2928 \mathrm{wbr} v\left(\mathrm{C}-\mathrm{H}_{\text {aliph }}\right), 1655 \mathrm{vs}$ $v(\mathrm{C}=\mathrm{O}), 1435 \mathrm{~m} v(\mathrm{C}=\mathrm{C}+\mathrm{C}=\mathrm{N}), 1395 \mathrm{~s}, 1289 \mathrm{~m}, 1100 \mathrm{~m}, 1057 \mathrm{~s}, 955 \mathrm{~s} v(\mathrm{C}-\mathrm{Br}), 829 \mathrm{~s}, 663 \mathrm{~m}$. Magnetic susceptibility: $\mu_{\text {eff }}(293 \mathrm{~K})=1.33$ B.M.

Synthesis of $\left[C u(\mu-4-I p z)_{2}(\mu-D M F)\right]_{n}, \mathbf{5}_{\mathbf{D M F}}$. The violet compound $\mathbf{5}_{\mathbf{D M F}}$ was synthesized similarly to $\mathbf{2}_{\mathbf{D M F}}$ by using 4-iodo-1H-pyrazole (4-IpzH) instead of pzH. Yield $0.469 \mathrm{~g}, 90 \%$. Elemental analysis calculated for: $\mathrm{C}_{9} \mathrm{H}_{11} \mathrm{CuI}_{2} \mathrm{~N}_{5} \mathrm{O}: \mathrm{C}, 20.69 ; \mathrm{H}, 2.12 ; \mathrm{N}, 13.40 \%$. Found: $\mathrm{C}, 20.75$; $\mathrm{H}, 2.09 ; \mathrm{N}, 13.29 \%$. IR $\left(\mathrm{cm}^{-1}\right): 3127 \mathrm{vw} v\left(\mathrm{C}-\mathrm{H}_{\text {arom }}\right), 2933 \mathrm{wbr}$ and $2855 \mathrm{w} v\left(\mathrm{C}-\mathrm{H}_{\mathrm{aliph}}\right), 1651 \mathrm{vs}$ $v(\mathrm{C}=\mathrm{O}), 1431 \mathrm{~m}, 1374 \mathrm{~s} v(\mathrm{C}=\mathrm{C}+\mathrm{C}=\mathrm{N}), 1281 \mathrm{~m}, 1098 \mathrm{~m}, 1053 \mathrm{~s}, 942 \mathrm{~s} v(\mathrm{C}-\mathrm{I}), 841 \mathrm{~s}, 662 \mathrm{~m}$. Magnetic susceptibility: $\mu_{\text {eff }}(293 \mathrm{~K})=1.38$ B.M.

Synthesis of $\left[\mathrm{Cu}(\mu-p z)_{2}\right]_{n}, 2$. Compound $\mathbf{2}_{\mathrm{DMF}}(0.5 \mathrm{mmol}, 0.135 \mathrm{~g})$ was maintained at $453 \mathrm{~K}$ under atmospheric pressure for two hours, to completely remove DMF, obtaining compound $\mathbf{2}$ as a light grey powder. Yield $0.096 \mathrm{~g}, 98 \%$. Elemental analysis calculated for: $\mathrm{C}_{6} \mathrm{H}_{6} \mathrm{CuN}_{4}: \mathrm{C}, 36.45 ; \mathrm{H}$, 3.06; N, 28.35\%. Found: C, 36.49; H, 3.09; N, 28.39\%. IR ( $\left.\mathrm{cm}^{-1}\right): 3128 \mathrm{w} v\left(\mathrm{C}-\mathrm{H}_{\text {arom }}\right), 1487 \mathrm{~m} v(\mathrm{C}=\mathrm{C}$ $+\mathrm{C}=\mathrm{N}), 1380 \mathrm{~s}, 1276 \mathrm{~m}, 1176 \mathrm{~m}, 1055 \mathrm{~s}, 888 \mathrm{w}, 784 \mathrm{~m}, 745 \mathrm{~s}, 757 \mathrm{~s}$. Magnetic susceptibility: $\mu_{\text {eff }}(293$ $\mathrm{K})=1.59$ B.M.

Synthesis of $\left[\mathrm{Cu}(\mu-4-\mathrm{Clpz})_{2}\right]_{n}, 3$. Compound $\mathbf{3}_{\mathbf{D M F}}(0.5 \mathrm{mmol}, 0.169 \mathrm{~g})$ was maintained at 453 $\mathrm{K}$ under atmospheric pressure for two hours, to completely remove DMF, obtaining compound $\mathbf{3}$ as a green powder. Yield $0.132 \mathrm{~g}, 99 \%$. Elemental analysis calculated for: $\mathrm{C}_{6} \mathrm{H}_{4} \mathrm{Cl}_{2} \mathrm{CuN}_{4}: \mathrm{C}, 27.03 ; \mathrm{H}$, $1.51 ;$ N, 21.02\%. Found: C, 26.92; H, 1.57; N, 20.97\%. IR ( $\left.\mathrm{cm}^{-1}\right): 3149 \mathrm{w} v\left(\mathrm{C}-\mathrm{H}_{\text {arom }}\right), 1394 \mathrm{~m} v(\mathrm{C}=\mathrm{C}$ $+\mathrm{C}=\mathrm{N}), 1293 \mathrm{~s}, 1212 \mathrm{~m}, 1153 \mathrm{~m}, 1060 \mathrm{vs}, 973 \mathrm{~s} v(\mathrm{C}-\mathrm{Cl}), 840 \mathrm{~s}, 828 \mathrm{~s}, 669 \mathrm{w}$. Magnetic susceptibility: $\mu_{\mathrm{eff}}(293 \mathrm{~K})=1.44$ B.M.

Synthesis of $\left[\mathrm{Cu}(\mu-4-\mathrm{Brpz})_{2}\right]_{n}, 4$. Compound $\mathbf{4}_{\mathbf{D M F}}(0.5 \mathrm{mmol}, 0.214 \mathrm{~g})$ was maintained at 453 $\mathrm{K}$ under atmospheric pressure for two hours, to completely remove DMF, obtaining compound $\mathbf{4}$ in the form of a light brown powder. Yield $0.176 \mathrm{~g}$, 98\%. Elemental analysis calculated for: $\mathrm{C}_{6} \mathrm{H}_{4} \mathrm{Br}_{2} \mathrm{CuN}_{4}$ : C, 20.27; H, 1.13; N, 15.76\%. Found: C, 20,31; H, 1.15; N, 15.77\%. IR $\left(\mathrm{cm}^{-1}\right)$ : $3149 \mathrm{w} v\left(\mathrm{C}-\mathrm{H}_{\text {arom }}\right), 1386 \mathrm{~m} v(\mathrm{C}=\mathrm{C}+\mathrm{C}=\mathrm{N}), 1287 \mathrm{~s}, 1201 \mathrm{~m}, 1153 \mathrm{~m}, 1153 \mathrm{~m}, 1058 \mathrm{vs}, 955 \mathrm{~s} v(\mathrm{C}-\mathrm{Br})$, $843 \mathrm{~s}, 826 \mathrm{~s}, 667 \mathrm{w}$. Magnetic susceptibility: $\mu_{\mathrm{eff}}(293 \mathrm{~K})=1.43$ B.M. 
Synthesis of $\left[\mathrm{Cu}(\mu-4-\mathrm{Ipz})_{2}\right]_{n}, \mathbf{5}$. Compound $\mathbf{5}_{\mathbf{D M F}}(0.5 \mathrm{mmol}, 0.261 \mathrm{~g})$ was maintained at 453 $\mathrm{K}$ under atmospheric pressure for two hours, to completely remove DMF, obtaining compound $\mathbf{5}$ in the form of a light brown powder. Yield $0.223 \mathrm{~g}$, 99\%. Elemental analysis calculated for: $\mathrm{C}_{6} \mathrm{H}_{4} \mathrm{CuI}_{2} \mathrm{~N}_{4}$ : C, 16.03; H, 0.90; N, 12.47\%. Found: C, 16.14; H, 0.88; N, 12.63\%. IR (cm $\left.{ }^{-1}\right): 3136 \mathrm{~W}$ $v\left(\mathrm{C}-\mathrm{H}_{\text {arom }}\right), 1373 \mathrm{~m} v(\mathrm{C}=\mathrm{C}+\mathrm{C}=\mathrm{N}), 1279 \mathrm{~s}, 1201 \mathrm{~m}, 1157 \mathrm{~m}, 1056 \mathrm{vs}, 942 \mathrm{~s} v(\mathrm{C}-\mathrm{I}), 839 \mathrm{~s}, 826 \mathrm{~s}, 664 \mathrm{w}$. Magnetic susceptibility: $\mu_{\text {eff }}(293 \mathrm{~K})=1.47$ B.M.

\subsection{Powder X-ray Diffraction Structural Characterization}

Microcrystalline powders of $\mathbf{1}, \mathbf{2}_{\mathrm{DMF}}-\mathbf{4}_{\mathrm{DMF}}, \mathbf{O C}-\mathbf{5}_{\mathrm{DMF}}$ and $\mathbf{O P}-\mathbf{5}_{\mathrm{DMF}}$ were deposited in the hollow of a $0.2 \mathrm{~mm}$ deep silicon zero-background plate. Data acquisitions were performed on a vertical-scan Bruker AXS D8 Advance $\theta: \theta$ diffractometer, equipped with a Lynxeye linear position-sensitive detector, an X-ray tube $(\mathrm{Cu} \mathrm{K \alpha}, \lambda=1.5418 \AA)$, a filter of nickel in the diffracted beam and the following optical components: primary beam Soller slits $\left(2.5^{\circ}\right)$, fixed divergence slit $\left(0.5^{\circ}\right)$, antiscatter slit $(8 \mathrm{~mm})$. The generator was set at $40 \mathrm{kV}$ and 40 $\mathrm{mA}$. After preliminary acquisitions for fingerprinting analysis, typically performed in the $3-$ $35^{\circ} 2 \theta$ range, diffraction data sets for a full structure determination were collected from $5^{\circ}$ up to $105^{\circ} 2 \theta$, with steps of $0.02^{\circ}$, and an overall scan time of approximately 12 hours. In case of $1,2_{\mathrm{DMF}}, \mathbf{O C}-\mathbf{5}_{\mathrm{DMF}}$ and $\mathbf{0 P -} \mathbf{5}_{\mathrm{DMF}}$, a peak search, followed by profile fitting, enabled us to estimate the low-to-medium-angle peak maximum positions which, through the Singular Value Decomposition algorithm ${ }^{49}$ implemented in TOPAS-R V3, ${ }^{50}$ provided approximate unit cell parameters for all the compounds. The space groups were assigned based on the observed systematic absences. Comparison of the PXRD patterns of $\mathbf{3}_{\mathrm{DMF}}$ and $\mathbf{4}_{\mathrm{DMF}}$ with that of $\mathbf{2}_{\text {DMF }}$ suggested that the three compounds share the same space group and similar unit cell parameters, as proved by whole powder pattern refinements carried out with the Le Bail method as implemented in TOPAS-R V3. Structure determination was carried out for $\mathbf{1}$, $\mathbf{2}_{\text {DMF }}$ and $\mathbf{5}_{\text {DMF }}$ with TOPAS-R V3 by a combined Monte Carlo/Simulated Annealing approach. A rigid body was used to describe the crystallographically independent portion of the $\mathrm{pz}^{-}$and $4-\mathrm{Xpz}^{-}(\mathrm{X}=\mathrm{Cl}, \mathrm{Br}, \mathrm{I})$ ligands, initially assigning average values to bond distances and angles. ${ }^{[I]}$ The position of their centre of mass and their orientation (when allowed by symmetry) were let to vary. Also DMF was modelled as a rigid body. ${ }^{[I]}$ Structure refinement was carried out with the Rietveld method as implemented in TOPAS-R V3. In the case of $\mathbf{3}_{\mathrm{DMF}}$ and $\mathbf{4}_{\mathrm{DMF}}$ the crystal and molecular structures were refined starting from the crystal structure of $\mathbf{2}_{\mathbf{D M F}}$, after introducing, in position 4 of the pyrazolate, a chlorine and bromine atom, respectively. During the final Rietveld refinement stages, the site occupation factor of the DMF molecule was refined without restraints, reaching a value 
lower than 1 in the case of $\mathbf{2}_{\text {DMF }}(0.8)$ and $\mathbf{5}_{\text {DMF }}(0.9)$. In addition, ligand bond distances (except the $\mathrm{C} / \mathrm{N}-\mathrm{H}$ distances) were refined in a restrained range of values. ${ }^{[\mathrm{III}]}$ In all cases, the background was modelled by a polynomial function of the Chebyshev type. A common, refined isotropic thermal factor $\left(B_{i s o}\right)$ was attributed to all atoms, except to the metal centres, to which the isotropic thermal factor $B_{\text {iso }}(M)=B_{\text {iso }}+2.0\left(\AA^{2}\right)$ was assigned. The peak profile was described by the Fundamental Parameters Approach. ${ }^{51}$ Anisotropic peak broadening was successfully described using second- or fourth-order spherical harmonics. Preferred orientation was observed in the case of $\mathbf{2}_{\mathbf{D M F}}-\mathbf{4}_{\mathbf{D M F}}$ (along the [110] pole) and $\mathbf{5}_{\mathrm{DMF}}$ (along the [100] pole) and corrected by the March-Dollase approach. ${ }^{52}$ The final Rietveld refinement plots are shown in Figures S18 and S19 of the Electronic Supplementary Information. The pertinent CIF files are supplied as Electronic Supplementary Information.

Crystal data for $[\mathbf{C u}(\mu-\mathbf{p z})(\boldsymbol{\mu}-\mathbf{O H})]_{\mathbf{n}}, \mathbf{1}: \mathrm{C}_{3} \mathrm{H}_{4} \mathrm{CuN}_{2} \mathrm{O}, \mathrm{FW}=147.62 \mathrm{~g} \mathrm{~mol}^{-1}$, orthorhombic, $P b c a, a=18.7113(9) \AA, b=6.7293(3) \AA, c=6.8436(1) \AA, V=861.71(6) \AA^{3}, Z=8, Z$ ' $=8$, $\rho=2.27 \mathrm{~g} \mathrm{~cm}^{-3}, F(000)=584, R_{\mathrm{Bragg}}=0.003, R_{\mathrm{p}}=0.013$ and $R_{\mathrm{wp}}=0.019$, for 4901 data and 42 parameters in the $7.0-105.0^{\circ}(2 \theta)$ range. CCDC No. ?.

Crystal data for $\left[\mathbf{C u}(\boldsymbol{\mu} \text {-pz })_{\mathbf{2}}(\boldsymbol{\mu} \text {-DMF })_{\mathbf{0} .8}\right]_{\mathbf{n}}, \mathbf{2}_{\text {DMF }}: \mathrm{C}_{8.4} \mathrm{H}_{11.6} \mathrm{CuN}_{4.8} \mathrm{O}_{0.8}, \mathrm{FW}=256.16 \mathrm{~g} \mathrm{~mol}^{-1}$, orthorhombic, Pnam, $a=12.1799(5) \AA, b=13.7527(6) \AA, c=7.0999(4) \AA, V=1189.28(9)$ $\AA^{3}, Z=8, Z^{\prime}=4, \rho=1.43 \mathrm{~g} \mathrm{~cm}^{-3}, F(000)=522.4, R_{\mathrm{Bragg}}=0.006, R_{\mathrm{p}}=0.026$ and $R_{\mathrm{wp}}=$ 0.038 , for 4876 data and 53 parameters in the 7.5-105.0 $(2 \theta)$ range. CCDC No.?

Crystal data for $\left[\mathbf{C u}(\boldsymbol{\mu}-\mathbf{4}-\mathbf{C l p z})_{2}(\boldsymbol{\mu} \text {-DMF })\right]_{\mathbf{n}}, \mathbf{3}_{\mathrm{DMF}}: \mathrm{C}_{9} \mathrm{H}_{11} \mathrm{Cl}_{2} \mathrm{CuN}_{5} \mathrm{O}, \mathrm{FW}=339.67 \mathrm{~g} \mathrm{~mol}^{-1}$, orthorhombic, Pnam, $a=13.7038(3) \AA, b=14.4516(3) \AA, c=7.1384(2) \AA, V=1413.70(6)$ $\AA^{3}, Z=8, Z^{\prime}=4, \rho=1.60 \mathrm{~g} \mathrm{~cm}^{-3}, F(000)=684, R_{\mathrm{Bragg}}=0.015, R_{\mathrm{p}}=0.024$ and $R_{\mathrm{wp}}=0.034$, for 4876 data and 47 parameters in the $7.5-105.0^{\circ}(2 \theta)$ range. CCDC No. ?.

Crystal data for $\left[\mathbf{C u}(\boldsymbol{\mu}-\mathbf{4}-\mathrm{Brpz})_{2}(\boldsymbol{\mu} \text {-DMF })\right]_{\mathbf{n}}, \mathbf{4}_{\mathbf{D M F}}: \mathrm{C}_{9} \mathrm{H}_{11} \mathrm{Br}_{2} \mathrm{CuN}_{5} \mathrm{O}, \mathrm{FW}=428.57 \mathrm{~g} \mathrm{~mol}^{-1}$, orthorhombic, Pnam, $a=14.1228(4) \AA, b=14.4113(3) \AA, c=7.1279(2) \AA, V=1450.72(6)$ $\AA^{3}, Z=8, Z^{\prime}=4, \rho=1.96 \mathrm{~g} \mathrm{~cm}^{-3}, F(000)=828, R_{\text {Bragg }}=0.019, R_{\mathrm{p}}=0.021$ and $R_{\mathrm{wp}}=0.031$, for 4851 data and 50 parameters in the $8-105.0^{\circ}(2 \theta)$ range. CCDC No.?

Crystal data for $\left[\mathbf{C u}(\boldsymbol{\mu} \text {-4-Ipz })_{2}(\boldsymbol{\mu} \text {-DMF })_{0.9}\right]_{\mathbf{n}}, \mathbf{o C}-\mathbf{5}_{\mathbf{D M F}}: \mathrm{C}_{8.6} \mathrm{H}_{10} \mathrm{I}_{2} \mathrm{CuN}_{4.9} \mathrm{O}_{0.9}, \mathrm{FW}=513.76 \mathrm{~g}$ $\mathrm{mol}^{-1}$, orthorhombic, Cmcm, $a=20.2680(5) \AA, b=9.5313(2) \AA, c=7.3586(1) \AA, V=$ 1421.53(6) $\AA^{3}, Z=16, Z^{\prime}=4, \rho=2.40 \mathrm{~g} \mathrm{~cm}^{-3}, F(000)=949.6, R_{\text {Bragg }}=0.054, R_{\mathrm{p}}=0.046$ and $R_{\mathrm{wp}}=0.069$, for 4851 data and 45 parameters in the $8-105.0^{\circ}(2 \theta)$ range. CCDC No.?

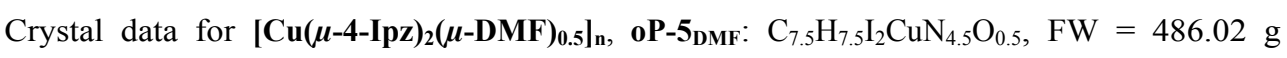
$\mathrm{mol}^{-1}$, orthorhombic, Pbnm, $a=20.1716(4) \AA, b=9.2333$ (2) $\AA, c=7.2913(1) \AA, V=1358.00(5)$ 
$\AA^{3}, Z=8, Z^{\prime}=4, \rho=1.19 \mathrm{~g} \mathrm{~cm}^{-3}, F(000)=892, R_{\mathrm{Bragg}}=0.024, R_{\mathrm{p}}=0.027$ e $R_{\mathrm{wp}}=0.036$, for 4851 data and 49 parameters in the $8-105.0^{\circ}(2 \theta)$ range. CCDC No. ?.

\section{4. m-5 DMF $_{\mathrm{DC}} \mathrm{C}-5_{\mathrm{DMF}}$ Phase Transformation Monitoring}

A 20-mg sample of as-synthesized $\mathbf{5}_{\mathbf{D M F}}$ (already a mixture of the pristine monoclinic and orthorhombic phases) was deposited in the hollow of a $0.2 \mathrm{~mm}$ deep silicon zero-background plate. Consecutive PXRD data acquisitions were performed on the vertical-scan Bruker AXS D8 described above in the $2 \theta$ range $8.0-35.0^{\circ}$ for a period of 5.4 hours.

\subsection{Variable-temperature Powder X-ray Diffraction}

To complement the thermal analysis, the thermal behaviour of $\mathbf{1}$ and $\mathbf{2}_{\mathbf{D M F}}-\mathbf{5}_{\mathbf{D M F}}$ was investigated in situ by variable-temperature PXRD. In the case of $\mathbf{5}_{\mathbf{D M F}}$, the study was carried out starting from the $\mathbf{0 C}-\mathbf{5}_{\mathbf{D M F}}$ phase. Using a custom-made sample heater (Officina Elettrotecnica di Tenno, Ponte Arche, Italy), 20-mg samples of the five compounds were heated in air with steps of $20 \mathrm{~K}$ and applying the experimental conditions collected in Table 3. A PXRD pattern was acquired at each step.

Table 3. Experimental conditions of the variable-temperature experiments carried out on compounds 1 and $2_{\text {DMF }}-5_{\text {DMF. }}$.

\begin{tabular}{lrr}
\hline Compound & T range (K) & 20 range $\left(^{\circ}\right)$ \\
\hline $\mathbf{1}$ & $303-623$ & $8.0-33.5$ \\
$\mathbf{2}_{\text {DMF }}$ & $303-703$ & $5.0-25.0$ \\
$\mathbf{3}_{\text {DMF }}$ & $303-683$ & $5.0-27.5$ \\
$\mathbf{4}_{\text {DMF }}$ & $303-623$ & $5.0-27.5$ \\
oC-5 $_{\text {DMF }}$ & $303-643$ & $5.0-27.5$ \\
\hline
\end{tabular}

\subsection{Computational Details}

The theoretical characterization of the systems $\mathbf{1}, \mathbf{2}_{\mathbf{D M F}}-\mathbf{4}_{\mathrm{DMF}}$ and $\mathbf{0 C}-\mathbf{5}_{\mathrm{DMF}}$ was performed with the quantum-mechanical ab initio CRYSTAL ${ }^{53}$ code which solves the Schrödinger equation for periodic systems adopting a basis set of localized orbitals, centred on each atom of the reference cell and obtained as linear combination of Gaussian-type functions (GTO). Both the Hartree-Fock (HF) and density functional methods (DFT) are available as well as several hybrid approaches. ${ }^{54}$ In particular, the calculations were performed adopting the B3LYP-D* hybrid exchange-correlation functional, ${ }^{55,56}$ where $\mathrm{D}^{*}$ stands for the D3 Grimme's a posteriori energy correction for dispersive interactions as 
tuned for molecular crystals. ${ }^{57}$ This approach enabled us to take into account weak binding effects that, however, can rule the interaction between the metal sites and coordinating molecular fragments, as in the case of $\mathrm{Cu}$ (II) and the oxygen atom of DMF. To avoid a possible overestimation of such effects and to determine their range of validity, some calculations were computed also at the B3LYP level. The basis set consisted of triple-z quality set (TZP) developed by Ahlrichs and co-workers ${ }^{58}$ supplemented by a set of polarization functions on all atoms, and can be considered a good compromise between accuracy and computational time for solid state calculations. The level of accuracy in evaluating the Coulomb and exchange integrals was controlled by five parameters, $\mathrm{T}_{1}-\mathrm{T}_{5}$, that were set to 7, 7, 7, 12 and 24 in the present calculations. The Hamiltonian matrix was diagonalized in a set of reciprocal k points ranging from 27 to 36 as a function of the reciprocal lattice symmetry and corresponding to the common shrinking factor of $4 .{ }^{59}$ Lattice constants and internal coordinates were simultaneously optimized using the analytical gradients and upgrading the numerical Hessian with the Shanno et al. algorithm. ${ }^{60}$ Default convergence criteria for the geometry optimization on the root mean square and on the absolute value of the largest component of the gradient and the estimated nuclear displacement were used. Infrared intensity for each normal mode was obtained by computing the dipole moment variation along the normal mode, adopting the Berry phase method. ${ }^{61}$

\section{AUTHOR INFORMATION}

\section{Corresponding Author}

*(Word Style "FA_Corresponding_Author_Footnote"). *(Word Style

"FA_Corresponding_Author_Footnote"). Give contact information for the author(s) to whom correspondence should be addressed.

\section{Present Addresses}

$\dagger$ If an author's address is different than the one given in the affiliation line, this information may be included here.

\section{Author Contributions}


The manuscript was written through contributions of all authors. All authors have given approval to the final version of the manuscript. $¥$ These authors contributed equally. (match statement to author names with a symbol)

\section{Funding Sources}

Any funds used to support the research of the manuscript should be placed here (per journal style).

\section{Foot Notes}

I. The non-standard space group $P 112_{1} / m$ was preferred to $P 2_{1} / m$ to have the $2_{1}$ screw axis along which the 1-D helices run parallel to the [001] crystallographic direction, as in $\mathbf{2}_{\mathbf{D M F}} \mathbf{F}^{-}$ $\mathbf{4}_{\text {DMF. }}$.

II. ${ }^{[\mathrm{II}]}$ Bond distances and angles for the rigid body describing the ligand: $\mathrm{C}-\mathrm{C}$ and $\mathrm{C}-\mathrm{N}$ of the pyrazole ring $1.36 \AA$; C-H of the pyrazole ring $0.95 \AA$; C-Cl $1.70 \AA$; C-Br $1.85 \AA$; C-I 2.05 $\AA$; pyrazole ring internal and external bond angles $108^{\circ}$ and $126^{\circ}$, respectively. Bond distances and angles for the rigid body describing the solvent: C-N, $1.45 \AA$; C-H, $0.95 \AA$; C$\mathrm{O}, 1.25 \AA$; angles at the nitrogen and amidic carbon atoms, $120^{\circ}$; angles at the carbon atoms of the methyl groups, $109.5^{\circ}$.

III. $\quad{ }^{[I I I]} \mathrm{C}-\mathrm{C}$ and $\mathrm{C}-\mathrm{N}$ bonds in the pyrazolate ligand, 1.32-1.38 $\AA$; $\mathrm{C}-\mathrm{N}$ bonds in the DMF

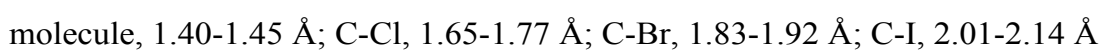

\section{References}

(1) Hoskins, B. F.; Robson, R. Infinite Polymeric Frameworks Consisting of Three Dimensionally Linked Rod-like Segments. J. Am. Chem. Soc. 1989, 111 (15), 5962-5964.

(2) Kostakis, G. E. Structural Design and Properties of Coordination Polymers; MDPI AGMultidisciplinary Digital Publishing Institute, 2018.

(3) Morsali, A.; Hashemi, L. Main Group Metal Coordination Polymers: Structures and Nanostructures; John Wiley \& Sons, 2017.

(4) Batten, S. R.; Neville, S. M.; Turner, D. R. Coordination Polymers: Design, Analysis and Application; Royal Society of Chemistry, 2008.

(5) Su, C.; Chen, C.; Zhang, J.; Kang, B. Silver (I) Coordination Polymers. Des. Constr. Coord. Polym. 2009, 5, 111-144.

(6) Lustig, W. P.; Li, J. Luminescent Metal-Organic Frameworks and Coordination Polymers as Alternative Phosphors for Energy Efficient Lighting Devices. Coord. Chem. Rev. 2018, 373, 
$116-147$

(7) Hasegawa, Y.; Nakanishi, T. Luminescent Lanthanide Coordination Polymers for Photonic Applications. RSC Adv. 2015, 5 (1), 338-353.

(8) Heine, J.; Müller-Buschbaum, K. Engineering Metal-Based Luminescence in Coordination Polymers and Metal-Organic Frameworks. Chem. Soc. Rev. 2013, 42 (24), 9232-9242.

(9) Binnemans, K. Lanthanide-Based Luminescent Hybrid Materials. Chem. Rev. 2009, 109 (9), $4283-4374$

(10) Loukopoulos, E.; Kostakis, G. E. Recent Advances of One-Dimensional Coordination Polymers as Catalysts. J. Coord. Chem. 2018, 71 (3), 371-410.

(11) Journaux, Y.; Ferrando-Soria, J.; Pardo, E.; Ruiz-Garcia, R.; Julve, M.; Lloret, F.; Cano, J.; Li, Y.; Lisnard, L.; Yu, P. Design of Magnetic Coordination Polymers Built from Polyoxalamide Ligands: A Thirty Year Story. Eur. J. Inorg. Chem. 2018, 2018 (3-4), 228247.

(12) Halcrow, M. A. Spin-Crossover Materials: Properties and Applications; John Wiley \& Sons, 2013.

(13) Weng, D.-F.; Wang, Z.-M.; Gao, S. Framework-Structured Weak Ferromagnets. Chem. Soc. Rev. 2011, 40 (6), 3157-3181.

(14) Talham, D. R.; Meisel, M. W. Thin Films of Coordination Polymer Magnets. Chem. Soc. Rev. 2011, 40 (6), 3356-3365.

(15) Givaja, G.; Amo-Ochoa, P.; Gómez-García, C. J.; Zamora, F. Electrical Conductive Coordination Polymers. Chem. Soc. Rev. 2012, 41 (1), 115-147.

(16) Gómez-Herrero, J.; Zamora, F. Coordination Polymers for Nanoelectronics. Adv. Mater. 2011, 23 (44), 5311-5317.

(17) Janiak, C.; Vieth, J. K. Themed Issue: Coordination Polymers: Structure and Function. New J. Chem 2010, 34, 2366-2388.

(18) Robin, A. Y.; Fromm, K. M. Coordination Polymer Networks with O-and N-Donors: What They Are, Why and How They Are Made. Coord. Chem. Rev. 2006, 250 (15-16), $2127-$ 2157.

(19) Biradha, K.; Sarkar, M.; Rajput, L. Crystal Engineering of Coordination Polymers Using 4, 4'-Bipyridine as a Bond between Transition Metal Atoms. Chem. Commun. 2006, No. 40, 4169-4179.

(20) Tăbăcaru, A.; Pettinari, C.; Galli, S. Coordination Polymers and Metal-Organic Frameworks Built up with Poly (Tetrazolate) Ligands. Coord. Chem. Rev. 2018, 372, 1-30.

(21) Pettinari, C.; Tăbăcaru, A.; Galli, S. Coordination Polymers and Metal-Organic Frameworks 
Based on Poly (Pyrazole)-Containing Ligands. Coord. Chem. Rev. 2016, 307, 1-31.

(22) Zhang, J. P.; Zhang, Y. B.; Lin, J. Bin; Chen, X. M. Metal Azolate Frameworks: From Crystal Engineering to Functional Materials. Chem. Rev. 2012, 112 (2), 1001-1033.

(23) Bai, S.; Young, D. J.; Hor, T. S. A. Nitrogen-Rich Azoles as Ligand Spacers in Coordination Polymers. Chem. Asian J. 2011, 6 (2), 292-304.

(24) Aromí, G.; Barrios, L. A.; Roubeau, O.; Gamez, P. Triazoles and Tetrazoles: Prime Ligands to Generate Remarkable Coordination Materials. Coord. Chem. Rev. 2011, 255 (5-6), 485546.

(25) Cingolani, A.; Galli, S.; Masciocchi, N.; Pandolfo, L.; Pettinari, C.; Sironi, A. The Competition between Acetate and Pyrazolate in the Formation of Polynuclear Zn (II) Coordination Complexes. Dalt. Trans. 2006, No. 20, 2479-2486.

(26) Masciocchi, N.; Galli, S.; Alberti, E.; Sironi, A.; Di Nicola, C.; Pettinari, C.; Pandolfo, L. Synthesis, Solid-State NMR, and X-Ray Powder Diffraction Characterization of Group 12 Coordination Polymers, Including the First Example of a C-Mercuriated Pyrazole. Inorg. Chem. 2006, 45 (22), 9064-9074.

(27) Casarin, M.; Corvaja, C.; di Nicola, C.; Falcomer, D.; Franco, L.; Monari, M.; Pandolfo, L.; Pettinari, C.; Piccinelli, F.; Tagliatesta, P. Spontaneous Self-Assembly of an Unsymmetric Trinuclear Triangular Copper (II) Pyrazolate Complex,[Cu3 (M3-OH)( $\mu-\mathrm{Pz}) 3$ (MeCOO) 2 $(\mathrm{Hpz})](\mathrm{Hpz}=$ Pyrazole). Synthesis, Experimental and Theoretical Characterization, Reactivity, and Catalytic Activity. Inorg. Chem. 2004, 43 (19), 5865-5876.

(28) Corvaja, C.; Casarin, M.; Franco, L.; Piccinelli, F.; Monari, M.; Falcomer, D.; Pettinari, C.; Di Nicola, C.; Pandolfo, L. One-Dimensional and Two-Dimensional Coordination Polymers from Self-Assembling of Trinuclear Triangular Cu(II) Secondary Building Units. Inorg. Chem. 2005, 44 (18), 6265-6276.

(29) Di Nicola, C.; Forlin, E.; Garau, F.; Lanza, A.; Natile, M. M.; Nestola, F.; Pandolfo, L.; Pettinari, C. Coordination Polymers Based on Trinuclear and Mononuclear CopperPyrazolate Building Moieties Connected by Fumarate or 2-Methylfumarate Ions. $J$. Organomet. Chem. 2012, 714.

(30) Di Nicola, C.; Forlin, E.; Garau, F.; Gazzano, M.; Lanza, A.; Monari, M.; Nestola, F.; Pandolfo, L.; Pettinari, C.; Zorzi, A.; et al. Coordination Polymers Based on the Trinuclear Triangular Secondary Building Unit $[\mathrm{Cu} 3(\mathrm{M} 3-\mathrm{OH})(\mu-\mathrm{Pz}) 3] 2+(\mathrm{Pz}=$ Pyrazolate $)$ and Succinate Anion. Cryst. Growth Des. 2013, 13 (1), 126-135.

(31) Di Nicola, C.; Garau, F.; Lanza, A.; Monari, M.; Pandolfo, L.; Pettinari, C.; Zorzi, A. Influence of the Solvent in the Formation of Different 1D and 2D Coordination Polymers 
from the Reaction of Copper(II) Phthalate with Pyrazole. Inorganica Chim. Acta 2014, 416, 186-194.

(32) Di Nicola, C.; Garau, F.; Gazzano, M.; Lanza, A.; Monari, M.; Nestola, F.; Pandolfo, L.; Pettinari, C. Interaction of the Trinuclear Triangular Secondary Building Unit [Cu3(M3$\mathrm{OH})(\mu-\mathrm{Pz}) 3] 2+$ with 4,4'-Bipyridine. Structural Characterizations of New Coordination Polymers and Hexanuclear CuII Clusters. $2^{\circ}$. Cryst. Growth Des. 2015, 15 (3), 1259-1272.

(33) Di Nicola, C.; Karabach, Y. Y.; Kirillov, A. M.; Monari, M.; Pandolfo, L.; Pettinari, C.; Pombeiro, A. J. L. Supramolecular Assemblies of Trinuclear Triangular Copper(II) Secondary Building Units through Hydrogen Bonds. Generation of Different Metal-Organic Frameworks, Valuable Catalysts for Peroxidative Oxidation of Alkanes. Inorg. Chem. 2007, $46(1), 221-230$.

(34) Di Nicola, C.; Garau, F.; Karabach, Y. Y.; Martins, L. M. D. R. S.; Monari, M.; Pandolfo, L.; Pettinari, C.; Pombeiro, A. J. L. Trinuclear Triangular Copper(II) Clusters - Synthesis, Electrochemical Studies and Catalytic Peroxidative Oxidation of Cycloalkanes. Eur. J. Inorg. Chem. 2009, No. 5, 666-676.

(35) Contaldi, S.; Di Nicola, C.; Garau, F.; Karabach, Y. Y.; Martins, L. M. D. R. S.; Monari, M.; Pandolfo, L.; Pettinari, C.; Pombeiro, A. J. L. New Coordination Polymers Based on the Triangular [Cu3(M3-OH)( $\mu-\mathrm{Pz}) 3] 2+$ Unit and Unsaturated Carboxylates. J. Chem. Soc. Dalt. Trans. 2009, No. 25, 4928-4941.

(36) Massignani, S.; Scatena, R.; Lanza, A.; Monari, M.; Condello, F.; Nestola, F.; Pettinari, C.; Zorzi, F.; Pandolfo, L. Coordination Polymers from Mild Condition Reactions of Copper (II) Carboxylates with Pyrazole (Hpz). Influence of Carboxylate Basicity on the Self-Assembly of the [Cu3 (M3-OH) $(\mu-\mathrm{Pz}) 3] 2+$ Secondary Building Unit. Inorganica Chim. Acta 2017, $455,618-626$.

(37) Pandolfo, L.; Pettinari, C. Trinuclear Copper (II) Pyrazolate Compounds: A Long Story of Serendipitous Discoveries and Rational Design. CrystEngComm 2017, 19 (13), 1701-1720.

(38) Casarin, M.; Cingolani, A.; Di Nicola, C.; Falcomer, D.; Monari, M.; Pandolfo, L.; Pettinari, C. The Different Supramolecular Arrangements of the Triangular [Cu 3(M3-OH) $(\mu-\mathrm{Pz}) 3] 2+$ $(\mathrm{Pz}=$ Pyrazolate) Secondary Building Units. Synthesis of a Coordination Polymer with Permanent Hexagonal Channels. Cryst. Growth Des. 2007, 7 (4), 676-685.

(39) Di Nicola, C.; Garau, F.; Gazzano, M.; Monari, M.; Pandolfo, L.; Pettinari, C.; Pettinari, R. Reactions of a Coordination Polymer Based on the Triangular Cluster [Cu3(M3-OH) $(\mu-$ Pz)3]2+ with Strong Acids. Crystal Structure and Supramolecular Assemblies of New Mono, Tri-, and Hexanuclear Complexes and Coordination Polymers. Cryst. Growth Des. 2010, 10 
(7), 3120-3131.

(40) Di Nicola, C.; Garau, F.; Gazzano, M.; Guedes Da Silva, M. F. C.; Lanza, A.; Monari, M.; Nestola, F.; Pandolfo, L.; Pettinari, C.; Pombeiro, A. J. L. New Coordination Polymers and Porous Supramolecular Metal Organic Network Based on the Trinuclear Triangular Secondary Building Unit $[\mathrm{Cu} 3(\mathrm{M} 3-\mathrm{OH})(\mu-\mathrm{Pz}) 3] 2+$ and 4,4'-Bypiridine. $1^{\circ}$. Cryst. Growth Des. 2012, 12 (6), 2890-2901.

(41) Forlin, E.; Lanza, A.; Di Nicola, C.; Monari, M.; Gazzano, M.; Nestola, F.; Pettinari, C.; Pandolfo, L. 1D and 3D Coordination Polymers Based on the Cu3(M3-OH)( $\mu-\mathrm{Pz}) 3$ and $\mathrm{Cu}(\mathrm{Hpz}) 3 \mathrm{SBUs}$ Connected by the Flexible Glutarate Dianion. Inorganica Chim. Acta 2018, 470, 385-392.

(42) Cingolani, A.; Galli, S.; Masciocchi, N.; Pandolfo, L.; Pettinari, C.; Sironi, A. SorptionDesorption Behavior of Bispyrazolato- Copper (II) 1D Coordination Polymers. J. Am. Chem. Soc. 2005, 127 (17), 6144-6145.

(43) Bencini, A.; Casarin, M.; Forrer, D.; Franco, L.; Garau, F.; Masciocchi, N.; Pandolfo, L.; Pettinari, C.; Ruzzi, M.; Vittadini, A. Magnetic Properties and Vapochromic Reversible Guest-Induced Transformation in a Bispyrazolato Copper(II) Polymer: An Experimental and Dispersion-Corrected Density Functional Theory Study. Inorg. Chem. 2009, 48 (9), 4044 4051.

(44) Casarin, M.; Forrer, D.; Pandolfo, L.; Pettinari, C.; Vittadini, A. Vapochromic Properties versus Metal Ion Coordination of $\beta$-Bispyrazolato-Copper (Ii) Coordination Polymers: A First-Principles Investigation. CrystEngComm 2015, 17 (2), 407-411.

(45) Fernando, I. R.; Surmann, S. A.; Urech, A. A.; Poulsen, A. M.; Mezei, G. Selective Total Encapsulation of the Sulfate Anion by Neutral Nano-Jars. Chem. Commun. 2012, 48 (54), $6860-6862$.

(46) Ahmed, B. M.; Mezei, G. From Ordinary to Extraordinary: Insights into the Formation Mechanism and PH-Dependent Assembly/Disassembly of Nanojars. Inorg. Chem. 2016, 55 (15), 7717-7728.

(47) Ehlert, M. K.; Rettig, S. J.; Storr, A.; Thompson, R. C.; Trotter, J. Metal Pyrazolate Polymers. Part 1. Synthesis, Structure, and Magnetic Properties of the $[\mathrm{Cu}(\mathrm{Pz}) 2]$ x Polymer. Can. J. Chem. 1989, 67 (11), 1970-1974.

(48) Ehlert, M. K.; Rettig, S. J.; Storr, A.; Thompson, R. C.; Trotter, J. Metal Pyrazolate Polymers. Part 2. Synthesis, Structure, and Magnetic Properties of [Cu (4-Xpz) 2] x Polymers (Where X= Cl, Br, Me, H; Pz= Pyrazolate). Can. J. Chem. 1991, 69 (3), 432-439.

(49) Coelho, A. A. Indexing of Powder Diffraction Patterns by Iterative Use of Singular Value 
Decomposition. J. Appl. Crystallogr. 2003, 36 (1), 86-95.

(50) Topas, V. 3.0; Bruker AXS: Karlsruhe, Germany, 2005.

(51) Cheary, R. W.; Coelho, A. A Fundamental Parameters Approach to X-Ray Line-Profile Fitting. J. Appl. Crystallogr. 1992, 25 (2), 109-121.

(52) Dollase, W. A. Correction of Intensities for Preferred Orientation in Powder Diffractometry: Application of the March Model. J. Appl. Crystallogr. 1986, 19 (4), 267-272.

(53) Dovesi, R.; Erba, A.; Orlando, R.; Zicovich-Wilson, C. M.; Civalleri, B.; Maschio, L.; Rérat, M.; Casassa, S.; Baima, J.; Salustro, S. Quantum-mechanical Condensed Matter Simulations with CRYSTAL. Wiley Interdiscip. Rev. Comput. Mol. Sci. 2018, 8 (4), e1360.

(54) Dovesi, R.; Saunders, V. R.; Roetti, C.; Orlando, R.; Zicovich-Wilson, C. M.; Pascale, F.; Civalleri, B.; Doll, K.; Harrison, N. M.; Bush, I. J. CRYSTAL17 User's Manual 2017, University of Torino. 2017.

(55) Becke, A. D. Becke's Three Parameter Hybrid Method Using the LYP Correlation Functional. J. Chem. Phys 1993, 98, 5648-5652.

(56) Lee, C.; Yang, W.; Parr, R. G. Development of the Colle-Salvetti Correlation-Energy Formula into a Functional of the Electron Density. Phys. Rev. B 1988, 37 (2), 785.

(57) Civalleri, B.; Zicovich-Wilson, C. M.; Valenzano, L.; Ugliengo, P. B3LYP Augmented with an Empirical Dispersion Term (B3LYP-D*) as Applied to Molecular Crystals. CrystEngComm 2008, 10 (4), 405-410.

(58) Schäfer, A.; Horn, H.; Ahlrichs, R. Fully Optimized Contracted Gaussian Basis Sets for Atoms Li to Kr. J. Chem. Phys. 1992, 97 (4), 2571-2577.

(59) Monkhorst, H. J.; Pack, J. D. Special Points for Brillouin-Zone Integrations. Phys. Rev. B 1976, 13 (12), 5188.

(60) Shanno, D. F. Conditioning of Quasi-Newton Methods for Function Minimization. Math. Comput. 1970, 24 (111), 647-656.

(61) Zicovich-Wilson, C. M.; Pascale, F.; Roetti, C.; Saunders, V. R.; Orlando, R.; Dovesi, R. Calculation of the Vibration Frequencies of A-quartz: The Effect of Hamiltonian and Basis Set. J. Comput. Chem. 2004, 25 (15), 1873-1881. 